\title{
REVIEW: FACTORS CONTROLLING THE DEUTERIUM CONTENTS OF SEDIMENTARY HYDROCARBONS
}

\author{
Alex L. Sessions \\ Division of Geological and Planetary Sciences, California Institute of Technology, Pasadena CA, USA \\ ALS@GPS.Caltech.edu
}

\section{ABSTRACT}

The hydrogen isotopic compositions of sedimentary hydrocarbon molecules are now being used to address a range of scientific questions, from paleoclimate to environmental reconstruction to understanding of petroleum systems. Here I review the environmental, biological, and physical/chemical factors that influence the $\mathrm{H}$ isotopic compositions of sedimentary hydrocarbons. A hierarchy of four main controls can be recognized: $i$ ) the composition of environmental water that serves as ultimate hydrogen source to the biosphere $\mathrm{ii}$ ) physiologic and metabolic processes in organisms that fix water hydrogen into organic molecules, iii) hydrogen exchange processes that alter $\mathrm{D} / \mathrm{H}$ ratios slowly over time under geologic conditions, and $i v$ ) kinetic fractionations that arise during the thermal conversion of sedimentary organic matter to liquid hydrocarbons. Variations in the terrestrial hydrologic cycle, and in biologic fractionations, create lipids with $\delta \mathrm{D}$ values spanning a huge range, and carrying abundant information about source organisms and environments. This information is gradually lost over geologic timescales due to hydrogen exchange, although the rates of this process appear to vary by orders of magnitude in clastic versus carbonate sediments. The $\mathrm{H}$ isotopes of hydrocarbons in many sediments of low to moderate thermal maturity may only be partially exchanged. Finally, additional kinetic fractionations are imposed during thermal cracking to generate mobile hydrocarbons. The $\delta \mathrm{D}$ values of sedimentary hydrocarbons are thus concluded to generally reflect a complicated combination of processes. Although it is tempting to view this as a failure of the isotopic record, there are numerous opportunities for understanding environment, diagenetic, and catagenetic processes if we can learn to quantitatively disentangle the competing fractionations. 


\section{INTRODUCTION AND HISTORY}

Quantitative analysis of the relative abundances of stable hydrogen isotopes, protium $\left({ }^{1} \mathrm{H}\right)$ and deuterium $\left({ }^{2} \mathrm{H}\right.$, or D), dates back more than 80 years to the earliest work of Urey and his students (Urey and Teal, 1935). However, most early studies of hydrogen isotopes were focused on environmental water, and the modern era of H-isotopic studies of organic matter arguably did not begin until 1967, when Zborowski measured the D content of fatty acids from sediments of the Mohole coring project (Zborowski et al., 1967). Shortly thereafter, Schiegl and Vogel (1970) and Smith and Epstein (1970) reported their respective surveys of the $\mathrm{H}$-isotope ratios of extant plants, noting that they are universally depleted in D relative to the environmental water around them. The former authors also noted that coal and oil had similar D/H ratios as wood and marine algae, respectively, and that natural gas had a much lower ratio than either. Over the next 4 decades there appeared numerous measurements of the isotopic composition of bulk organic matter, including the landmark 1980 contribution by Estep and Hoering "Biogeochemistry of the stable hydrogen isotopes." Yet it seems fair to say that - with two main exceptions - such bulk measurements did not figure prominently in organic geochemical research. The two exceptions are cellulose (Sternberg et al., 1984; Feng and Epstein, 1995) and methane (Schoell, 1980; Whiticar et al., 1986), both pure compounds that can be isolated in sufficient quantity for "bulk" isotopic analysis.

The problem was - and still is - that many organic compounds contain hydrogen in functional groups where it is rapidly exchangeable with water and/or mineral H (Schimmelmann et al, 2006). Methane does not, so its isotope ratio was readily interpretable; similarly, cellulose could be nitrated to yield a nonexchangeable product. But for complex sedimentary organic matter, comprising a spectrum of compounds with widely varying propensity for $\mathrm{H}$-isotopic exchange, interpretation of bulk $\mathrm{D} / \mathrm{H}$ measurements was tenuous at best. Isotopic studies of whole oils could do little more than note the similarity in ${ }^{2} \mathrm{H}$ content to the presumed source organic matter (Rigby et al., 1981; Yeh and Epstein, 1981).

The invention of compound-specific analytical techniques in the late 1990's was game-changing for the study of hydrogen isotopes in organic molecules (Summons et al., 2008). These techniques married the separation and specificity of gas chromatography with the continuous, online conversion to $\mathrm{H}_{2}$ afforded by pyrolysis (Burgoyne and Hayes, 1998; Hilkert et al., 1999; Scrimgeour et al., 1999), allowing measurements of nanogram quantities of individual molecules isolated from sediments or crude oils. Obtaining 100s of nanograms of hydrocarbons is usually quite feasible, with the last major analytical hurdle being the separation of analytes from complex mixtures. Relevant analytical methodologies were reviewed by Sessions (2006). The compound-specific approach to $\mathrm{H}$ isotopes has the dual benefits of both simplifying source/product relationships and avoiding exchangeable H. By the early 2000's commercial instruments were available and fueling a wave of renewed interest in organic D/H studies, in paleoclimate 
(Sauer et al., 2001), in Earth History (Dawson et al., 2004), and in petroleum systems (Li et al., 2001). These advances notwithstanding, our knowledge of $\mathrm{D} / \mathrm{H}$ behavior at the molecular level is based on little more than a decade of study, and so there remains much that is still incompletely understood.

In this review, I attempt to summarize our current understanding of the processes controlling hydrogenisotopic compositions of hydrocarbon molecules, with reference both to the biomarkers of interest to Earth Historians and the oil-forming compounds of interest to petroleum geochemists. In doing so, I have confined myself largely to studies examining the composition of individual molecules, as these afford the greatest insight. Bulk oils and kerogens are of course collections of individual molecules, so many of the same insights are relevant. However, I do not review the extensive (and generally older) literature on bulk $\mathrm{D} / \mathrm{H}$ measurements of hydrocarbons and kerogen. The reader is referred to Schimmelmann et al (2006) as a starting point for that subject. I have also largely sidestepped the extensive literature on $\mathrm{D} / \mathrm{H}$ fractionations in plant leaf waxes, of interest to paleoclimatologists, as that subject has been recently reviewed by Sachse et al (2012). Sections 3-6 of this review take a process-based approach, looking at the environmental, biological, and physical/chemical processes that influence $\mathrm{D} / \mathrm{H}$ ratios along the path from environmental water to lipids to sedimentary hydrocarbons to produced oils. Section 7 takes a more phenomenological approach, summarizing observations of hydrocarbon isotopic composition from several major petroleum basins and attempting to reconcile those with what is known about process. Although the factors controlling the deuterium contents of sedimentary hydrocarbons are complex, I conclude that there are numerous possible applications for $\mathrm{D} / \mathrm{H}$ measurements. For the biogeochemist, paleoenvironmental and hydroclimate reconstruction, terrestrial vs marine source apportionment, distinguishing microbial metabolic pathways, and understanding diagenetic pathways all appear promising. In the area of petroleum geochemistry, compound-specific $\delta \mathrm{D}$ measurements could potentially be used in assessing organic matter sources, differentiating source rocks, correlating sources rocks with oils, and perhaps even in organic matter thermal maturity studies.

\section{HieraRchy of Controls}

A hierarchy of four main controls on the H-isotopic composition of hydrocarbons can be recognized. They are $i$ ) the composition of environmental water that serves as ultimate hydrogen source to the biosphere ii) physiologic and metabolic processes in organisms that fix water hydrogen into organic molecules, iii) hydrogen exchange processes that alter ${ }^{2} \mathrm{H} /{ }^{1} \mathrm{H}$ ratios slowly over time under geologic conditions, and $i v$ ) kinetic fractionations that arise during the thermal conversion of sedimentary organic matter to mobile hydrocarbons. These processes are not mutually exclusive, and the relative importance 
of each depends strongly on the circumstances of a particular environment. For example, terrestrial organic matter deposited at high latitude will be strongly influenced by $(i)$, whereas marine organic matter would be more strongly affected by (ii). (iii) is obviously more important for older deposits, but also depends strongly on temperature history, mineralogy, and other factors, while (iv) may vary more strongly with thermal maturity. These processes can interfere both positively and negatively, yielding exaggerations or cancellations of changes in isotopic composition. For example, increasing $\mathrm{H}$ isotope exchange tends to yield more positive $\delta \mathrm{D}$ values, whereas kinetic effects associated with cracking tend to produce more negative values, and both are evident in active petroleum systems. The $\delta \mathrm{D}$ scale, being a scalar quantity, cannot be uniquely diagnostic for all combinations of processes.

A convenient starting point for considering hydrogen isotopes in sedimentary organic molecules is environmental water, which varies in its isotopic composition as a result of fractionations in the hydrologic cycle. Water is obviously the sole source of hydrogen to all plants, but also (and less obviously) the main source for most heterotrophic microbes. Biology harnesses a variety of energy sources, including both sunlight and a variety of chemical redox couples, to "fix" inorganic hydrogen (water) into organic hydrogen (lipids and other biomolecules). This feat is accompanied by a wide range of isotopic fractionations, and a full appreciation of them requires understanding the biologic conservation of energy and reducing power, as well as the synthesis of relevant biomolecules. Once these molecules are deposited in sediments, they are subject to a variety of processes that can lead to the exchange of hydrogen atoms with other molecules in the environment - including water - without alteration of the parent carbon skeleton. This process is somewhat unique to hydrogen, and is necessarily accompanied by changes in isotope ratios. The timescales for such hydrogen exchange in the natural environment range from seconds to billions of years, with rates being strongly influenced by temperature and mineral catalysis. They are thus one of the hardest parts of this system to grapple with. Kinetic fractionations occurring during kerogen (and oil) cracking are liable to be similarly complicated, but have not yet been thoroughly studied. Nevertheless, some broad trends have been recognized, particularly the progressive depletion of ${ }^{2} \mathrm{H}$ in the products of cracking.

\section{ORIGins OF the SignaL: HydROGEN ISOTOPES IN ENVIRONMENTAL WATERS}

Environmental water serves as the primary source of hydrogen to photosynthesis, thus its isotopic composition exerts first-order control over the $\delta \mathrm{D}$ values of organic $\mathrm{H}$. For marine organisms, this is a relatively stable starting point, with seawater being well-mixed with an average $\delta \mathrm{D}$ value close to $\sim 0 \%$. Small variations, $<5 \%$ in $\delta \mathrm{D}$, are driven by evaporation and freshwater inputs (Craig and Gordon, 1965), 
whereas more extreme departures are rare. The $\delta \mathrm{D}$ value of seawater has likely been quite stable over most of Earth's history (see section 3.4). In contrast, terrestrial vegetation draws on meteoric waters that are highly variable in isotopic composition over time and space, making it difficult to pin down a reference point for organic $\mathrm{H}$. Nevertheless, a number of broad geographic patterns in water $\mathrm{D} / \mathrm{H}$ do exist and can be observed in sedimentary organic matter.

Isotopic variability in the hydrologic cycle is driven almost entirely by fractionations accompanying the physical conversion of water between the solid, liquid, and vapor phases. Precipitation can vary markedly in $\delta \mathrm{D}$, often by tens of permil, between seasons. Different hydrologic reservoirs, including the atmosphere, surface waters, and groundwaters, have very different residence times and so integrate over differing timescales. The details of this complex system have been well studied over the past 5 decades, and are the subject of numerous excellent reviews and texts (e.g., Clark and Fritz, 1997; Aggarwal et al., 2009) to which the reader is referred for mechanistic detail. Here I simply summarize the resulting patterns of ${ }^{2} \mathrm{H}$ distribution in environmental waters as relevant to the biosphere.

\subsection{Meteoric precipitation.}

At the broadest scale, the hydrologic cycle is supplied with water vapor by evaporation from the warm tropical oceans, which it returns to the Earth's surface as precipitation when air masses cool and water vapor condenses. The multiple phase changes involved in this cycle drive strong isotopic fractionations due to both equilibrium and kinetic isotope effects, and lead to large $\mathrm{D} / \mathrm{H}$ variations in environmental water. Due to the strong exponential dependence of water vapor pressure on temperature, as given by the Clausius-Clapeyron relation, more than $70 \%$ of global atmospheric water vapor is derived from the tropical oceans (Craig and Gordon, 1965), mainly the warmest waters in the western Pacific. As air masses move to higher altitude and latitude, they cool and liquid water (rain) begins to condense and fall. This precipitation is D-enriched relative to the water vapor, but because air masses behave as effectively closed systems both cloud vapor and precipitation evolve towards more D-depleted compositions as rain continues to fall (Fig 1). And since precipitation forms only when clouds cool, this leads to a strong correlation between air temperature and precipitation $\delta \mathrm{D}$. The process is often referred to as a "Rayleigh distillation" of atmospheric water vapor. Clark and Fritz (1997, Ch. 2) provide an excellent, and much more complete, description of this phenomenon.

The resulting first-order pattern from this hydrologic distillation is shown in Fig 2. Three general components of the pattern can be recognized. The first is the 'latitude' effect, in which precipitation $\delta \mathrm{D}$ decreases poleward. This can be understood in a straightforward way as resulting from the fact that it is colder at higher latitudes, thus these locations are further down the "Rayleigh distillation curve" (i.e., 
further to the right in Fig 1). The second effect is the 'altitude' effect, in which precipitation $\delta \mathrm{D}$ drops with increasing altitude. This is again a simple consequence of temperature, although an interesting corollary is that the leeward (rain shadow) side of mountain ranges is typically D-depleted relative to the windward side, even though it is no colder and often warmer. This is due to the large amount of moisture wrung out of clouds as they rise over mountain ranges. A third aspect of the distribution is the 'continental' effect, in which $\delta \mathrm{D}$ values tend to drop towards the interior of continents. Again, this can be explained by these locations lying further along the distillation curve, with storms arising over the oceans and progressing inland. Rozanski et al (1993) provide a more detailed description of these phenomena. A second-order question is whether mean annual precipitation $\delta \mathrm{D}$ is the appropriate metric for comparing with plants that grow mainly in the spring and summer, at least outside the tropics. Some recent reports have suggested that the leaf waxes of certain plants are sensitive only to environmental water composition during a brief period of leaf flush (e.g., Tipple et al., 2013), while others have shown that they can respond to changing water isotopes throughout the growing season (Sessions, 2006; Newberry et al., 2015). Since precipitation $\delta D$ can vary seasonally by many tens of permil (generally being D-enriched during summer relative to winter), such timing effects potentially have a substantial impact on predicted $\delta \mathrm{D}$ values of organic matter. An additional complication is that plants may variably access shallow soil waters that reflect only recent precipitation and are more strongly evaporated, or deeper groundwaters that average over much longer periods (e.g. Meinzer et al., 1999). Ultimately, while the scale of these variations will matter significantly for paleoclimate studies, they are likely too small to be resolved in the isotopic composition of ancient sedimentary hydrocarbons.

\subsection{Lakes and Evaporative Basins.}

The evaporation of water from any reservoir, including leaves, soils, rivers, lakes, and even the ocean, will preferentially enrich $\mathrm{D}$ in the residual liquid phase. This is not a perfectly equilibrium process, due to kinetic fractionation as water vapor diffuses through the saturated boundary layer immediately above the liquid into the turbulent air column. The fractionation is empirically observed to be $\sim 82 \%$ at $25{ }^{\circ} \mathrm{C}$ and a relative humidity of 50\% (Gonfiantini, 1986), increasing slightly with lower humidity. Thus we should expect all surface water bodies to be at least slightly D-enriched relative to source precipitation.

The impact of this rather large fractionation on the isotopic composition of the lake (river, basin, etc) depends on the size of the evaporative flux relative to other (non-fractionating) sources and sinks, as well as the size of the reservoir. As a simple example, evaporation of $1 \%$ of a lake's volume at $25{ }^{\circ} \mathrm{C}$ and $50 \%$ $\mathrm{RH}$ would represent a change in isotopic composition of the remaining water of approximately $1 \% \times 82 \%$ $=0.8 \%$, which is hardly detectable. At least $10 \%$ of the lake would have to be evaporated to have a 
substantial impact, and significant inflow of water would lessen the effects proportionately. Moreover, it is difficult to drive surface water bodies far out of isotopic equilibrium with atmospheric water vapor because of isotopic exchange between liquid water and overlying water vapor. These competing processes were considered in detail by Craig and Gordon (1965), who formulated the widely used model for lake water isotopic composition:

$\delta_{E}=\frac{\alpha_{L / V} \cdot \delta_{L}-R H \cdot \delta_{A}-\varepsilon_{L / V}-12.5(1-R H)}{1-R H+10^{-3}(12.5(1-R H))}$

where $\delta_{\mathrm{E}}$ and $\delta_{\mathrm{A}}$ are the isotopic compositions of evaporating water vapor, and of background atmospheric water vapor, respectively. The model is reviewed in a more approachable fashion by Gibson and Edwards (2002). Empirically, we observe that even the most strongly evaporative lakes and basins in the modern world are only modestly D-enriched, e.g., the Dead Sea (+5\%; Gat, 1984), Lake Chala (+8\%; Payne, 1970), or salt ponds of the Christmas Islands (up to $+16 \%$; Sachse and Sachs, 2008).

In general then, deep lakes, inland seas, and oceans in all climates, and most lakes in cold/wet climates where evaporation is minimal, are not strongly affected by evaporative fractionations, certainly not at a level that would be detectable in sedimentary hydrocarbons. Evaporation tends to be significant for the isotopic record only in relatively arid regions, and especially in closed basins where evaporation greatly exceeds outflow. Even then lake waters may only be D-enriched by $10-15 \%$ relative to seawater, a difference that would be near the edge of detectability in hydrocarbons.

For the organic geochemist, there are two important messages. First, the $\delta \mathrm{D}$ values of lakes and restricted seas - and thus of organic matter in these environments - can be modestly D-enriched relative to their source water by evaporation. Second, water $\delta \mathrm{D}$ values above those of seawater (i.e., positive $\delta \mathrm{D}$ values) are reliable indicators of strongly evaporative, low-latitude systems. All else being equal, organic $\delta \mathrm{D}$ values higher than those of marine organic matter should be indicative of evaporative/hypersaline systems. These types of signals have been used, for example, to good effect in distinguishing marine from hypersaline source rocks in the Potiguar Basin of Brazil (Santos Neto and Hayes, 1999).

\subsection{Soil and Leaf Waters.}

When considering the $\mathrm{H}$-isotopic composition of terrestrial organic matter, an additional complication is introduced by the evaporation of water from soils and leaves. Just as for evaporation from lakes, the process drives a D-enrichment of soil and leafwater reservoirs, and will result in a corresponding increase in $\delta \mathrm{D}$ values of organic matter. In contrast, however, the magnitude of these effects are not easily modeled or quantified, for a variety of reasons. In soils, the evaporation of water becomes transportlimited by the diffusion of water vapor through soil pores, and thus drops off exponentially with depth. 
For example, in a seasonally dry tropical forest, Meinzer et al (1999) measured 45\%o enrichments in $\delta D$ of soil water at $0.1 \mathrm{~m}$ depth, but only $5 \%$ enrichment at $1 \mathrm{~m}$ depth. Because different plant types can have dramatically different rooting depths, the isotopic composition of the soil water they are accessing can be difficult to generalize. Moreover, plants living in arid regions tend to have deeper roots, which counteracts the effects of soil water evaporation. For these reasons, West et al (2007) have argued that over large spatial scales plant water isotopic composition tends to follow that of mean annual precipitation, and is not greatly affected by soil water evaporation.

A much more pervasive effect is the evaporation of water vapor from leaf surfaces, termed transpiration. Very detailed models of the isotopic consequences (for both $\delta^{18} \mathrm{O}$ and $\delta \mathrm{D}$ ) of leaf transpiration have been developed, but their details are beyond the scope of this review (e.g., see Flanagan et al., 1991; Kahmen et al., 2008). These models show that the magnitude of leafwater D enrichment is linearly proportional to the difference in water vapor pressure inside and outside the leaf, known as the vapor pressure deficit (VPD). At a VPD of $1.0 \mathrm{kPa}$ (equivalent to $76 \% \mathrm{Rh}$ at $30{ }^{\circ} \mathrm{C}$ ), steady-state $\mathrm{D} / \mathrm{H}$ enrichment of leaf water in Phaseolus vulgaris (bean plant) was measured at $<5 \%$, whereas at a VPD of $3.0 \mathrm{kPa}(26 \% \mathrm{Rh}$ at $30{ }^{\circ} \mathrm{C}$ ) it was $\sim 50 \%$. Transpiration in other plants will differ depending on the stomatal conductance of those species, but Phaseolus is likely near the high end of the range. These data thus span the range of conditions likely to be encountered in nature, and so bracket the magnitude of fractionations to be expected for leafwater. While it is generally true that plants living in drier environments will experience greater leafwater D enrichment, it is not always true. For example, succulents living in extremely arid conditions have evolved a variety of physiologic means to conserve water, and thus limit fractionation due to transpiration (e.g. Feakins and Sessions, 2010).

Whether or not transpiration-induced $\mathrm{D}$ enrichments of leaf water will be reflected in the $\delta \mathrm{D}$ values of leaf wax compounds has been a much more contentious question. On one hand, several greenhouse (McInerney et al., 2011) and field (Hou and Huang, 2008; Feakins and Sessions, 2010; Gao et al., 2014) studies have observed no significant change in net fractionation between leaf waxes and precipitation as a function of relative humidity. On the other hand, Sachse et al (2012) have compiled literature values for the $\mathrm{D} / \mathrm{H}$ fractionations between $n-\mathrm{C}_{29}$ alkanes from plant leaves and mean annual precipitation, as a function of both relative humidity and annual evaporation (Fig 3). Although there is considerable scatter, these data do indicate a D-enrichment of about 50-60\% on average for plants living at relative humidity < $70 \%$ (or annual evapotranspiration $<500 \mathrm{~mm}$ ) relative to those living at $>70 \% \mathrm{Rh}(>500 \mathrm{~mm} \mathrm{ET}$ ). Because plant morphotypes and physiologies are correlated with environmental variables, the trends in Fig 3 should be viewed as likely reflecting a combination of both transpirational and physiologic effects. 
In summary, evaporation of water from soils and plants does lead to an increase in the $\delta \mathrm{D}$ value of leaf waters, but whether this signal is passed on to leaf waxes is currently uncertain, and perhaps variable. In any case, such effects should range from $0 \%$ in wet regions to at most $\sim 50 \%$ in arid regions. This signal is large enough to be potentially observable in hydrocarbons from immature sediments.

\subsection{Seawater Over Time}

The modern oceans are quite well mixed with respect to their isotopic composition, as discussed above. A further question is whether this isotopic composition has changed appreciably over geologic timescales, and whether this might affect the isotopic composition of marine organic matter. Two mechanisms that could potentially alter the $\delta \mathrm{D}$ of seawater can be considered: the growth of ice sheets during glacial intervals, and the partitioning of water between oceans and hydrous minerals in the mantle. The isotopic composition of porewaters recovered from deep-sea sediment cores indicate typical shifts in $\delta \mathrm{D}$ of $3-6 \%$ associated with glacial/interglacial cycles, with the ocean becoming D-enriched during glacial intervals as more D-depleted ice is stored on land (Friedman and Hardcastle, 1988). A change in $\delta \mathrm{D}$ of $\sim 10 \%$ is associated with growth of the Antarctic ice sheet in the Miocene, and this likely represents the upper limit on changes in mean seawater isotopic composition that can be induced by the hydrologic cycle.

On longer timescales, imbalance between the addition of water to the mantle by hydrothermal alteration and burial of hydrous sedimentary minerals, and its return to the surface by dehydration of subducting plates, could lead to significant shifts in isotopic composition. This is true because the fractionation between liquid water and mineral $\mathrm{OH}$ groups is large, typically 30-100\%. Direct measurements of the Hisotopic composition of ophiolites suggest that the $\delta \mathrm{D}$ value of seawater has remained within $0 \pm 20 \%$ for at least the Phanerozoic (Sheppard and Epstein, 1970), and perhaps as far back as the Paleoproterozoic (Lecuyer et al., 1998). Lecuyer et al. have also considered the issue from a theoretical perspective, and show that as the mass of the ocean rises due to net transfer of water from the mantle to the surface, its $\delta \mathrm{D}$ value should fall. In their model, a $20 \%$ increase in ocean mass corresponds to a $\sim 20 \%$ decrease in seawater $\delta \mathrm{D}$, while a $20 \%$ decrease in mass yields a $\sim 10 \%$ increase in $\delta \mathrm{D}$. Based on sedimentary records suggesting that continental freeboard has been relatively constant at least since the middle Proterozoic, they argue for changes in seawater $\delta \mathrm{D}$ of $<20 \%$ over that timescale. Although changes of this magnitude would be easily resolved in direct measurements of water, they are likely near the limit of what could be recognized by analyses of the $\delta \mathrm{D}$ values of organic compounds. In certain hydrothermal settings, however, water isotopic composition can vary much more substantially, and in this case sedimentary hydrocarbon $\delta \mathrm{D}$ values can potentially provide valuable clues into the hydrology of the system (e.g., Williford et al., 2011). 


\section{THE FINGERPRINTS OF LIFE: BIOCHEMICAL FRACTIONATIONS IN LIPIDS}

Fractionations accompanying the biological fixation of inorganic hydrogen (mainly $\mathrm{H}_{2} \mathrm{O}$, but also $\mathrm{H}_{2}$ ) into organic matter constitute the next important step in determining the $\delta \mathrm{D}$ values of sedimentary organic compounds. These reactions largely explain the ubiquitous D-depletion of organic matter relative to environmental water (Estep and Hoering, 1980). Whereas pathways of C-and N-fixation are well defined, those for hydrogen are more nebulous. This obstacle arises primarily because many biochemical reactions, e.g. isomerization, oxidation/reduction, saturation/desaturation, etc., result in the exchange of C-bound $\mathrm{H}$ with water (Schimmelmann et al., 2006). Thus when considering lipids, the defining step with respect to their H-isotopic composition seems to be the biosynthesis of the lipid molecules themselves, not the original reduction of water in photosynthesis. Fortunately, lipid biosynthetic pathways are widely conserved across biology, so only a relatively few number of cases need be considered. The situation contrasts markedly with that of carbon, wherein a single enzymatic step during carbon fixation leads to

${ }^{13} \mathrm{C}$-depletion of virtually all downstream products.

Biosynthetic fractionations result in lipids that are depleted in D relative to environmental water by typically $100-250 \%$, albeit with outliers extending up to $+200 \%$ and down to $-450 \%$. Thus biological lipids, and their resulting geologic molecular fossils, are almost always among the most D-depleted compounds observed in nature (Sessions et al., 1999). Although the total range of fractionations is large, several important trends can be identified, namely the isotopic contrast between isoprenoid vs $n$-alkyl carbon skeletons, and that between the lipids of photoautotrophs, heterotrophs, and chemoautotrophs. The pathways and mechanisms involved in these processes are complex, and this review attempts only a brief and very broad overview. More complete and biochemically detailed treatments have been provided by Schmidt et al. (2003), Robins et al. (2003), X. Zhang et al. (2009), and Sachse et al. (2012). In summarizing this information, I rely primarily on data from natural environments, rather than on detailed culture- and greenhouse-based studies, in the belief that these will be more representative of the patterns observed in Nature.

\subsection{Differences between lipids with isoprenoid and n-alkyl skeletons.}

Sessions et al (1999) first noted the dichotomy between $\delta \mathrm{D}$ values of fatty acids and sterols in marine algae, with sterols being D-depleted by typically $100 \%$ relative to fatty acids. This pattern has since been observed in essentially every organism studied, and is thought to be ubiquitous. The most comprehensive survey of lipid $\delta \mathrm{D}$ values in a modern marine sediment was provided by Li et al (2009) for the Santa 
Barbara Basin (SBB). Their dataset includes $>1100$ analyses of lipids from the top $2 \mathrm{~m}$ of a single sediment core taken at the SBB depocenter, and nicely summarizes this offset, now generalized to include virtually all straight-chain and isoprenoid lipids (Fig 4). The mechanistic basis for the offset is not well known, although it is commonly assumed to derive from the fundamental differences in biosynthetic pathway of these two groups of molecules (see Sessions et al., 1999 for discussion).

Marine lipids with $n$-alkyl carbon skeletons, including $n$-alkanes, $n$-alkanols, ketones, and fatty acids, have a mean $\delta \mathrm{D}$ value near $-150 \%$, i.e. a $150 \%$ depletion of $\mathrm{D}$ relative to seawater. The distribution spans some $200 \%$, but this large range is exaggerated by the inclusion of some bacterial fatty acids with unusual compositions (see discussion below). When considering only the most abundant molecules, which are presumably the products of marine algae, the distribution is considerably tighter and slightly more negative, typically $-170 \pm 50 \%$. Subtle differences in $\delta \mathrm{D}$ values between compound classes (e.g., alkanes, alkanol, and acids) have been noted, though these are typically of order 20-30\% (Li et al., 2009; Hou et al., 2007). There is also some uncertainty about whether this distribution is representative of all algae in all oceanic regimes, as some culture-based studies have indicated possible significant deviations due to growth rate (Z. Zhang et al., 2009), salinity (Schouten et al., 2006; Sachs and Schwab, 2011), light intensity (Yang et al., 2009), and others. Without any further environmental data to test these hypotheses, $-170 \%$ remains the best current estimate of fractionation in marine primary production.

Lipids with isoprenoid skeletons fall into two main groups. Cyclic triterpenoids, mainly sterols and hopanols and their respective diagenetic products (steranes, hopanes, etc) center around $-270 \%$, or about $100 \%$ more D-depleted than coexisting $n$-alkyl lipids. Once again, the relatively broad distribution of $\delta \mathrm{D}$ values is largely a consequence of differences between (eukaryotic) sterols and (bacterial) hopanols. The second, more D-depleted group, comprises phytol and its diagenetic products (phytenes, phytanoic acids, etc). When observed in plants, phytol is universally observed to be highly D-depleted relative to environmental water, sometimes by nearly $500 \%$. In SBB, the $\delta \mathrm{D}$ values of phytol center around $-360 \pm$ $50 \%$. Although such strong depletions are virtually never observed in geologic hydrocarbons like pristane and phytane, the existence of a strong contrast in $\delta \mathrm{D}$ values of primary biomolecules can be a useful recorder of isotopic exchange (see section 5). Phytol and triterpenols share a common pathway for the biosynthesis of their isoprene monomers, so this large isotopic contrast is somewhat unexpected.

Chikaraishi et al (2009) have attributed the difference to large D-depletions during the hydrogenation of geranylgeraniol to phytol based on measurements in sprouting cucumber plants. While the extrapolation of this mechanism to marine phytoplankton remains uncertain, the strong D-depletion of phytol does appear to be ubiquitous. The polycyclic aromatic compound perylene presents an interesting application of these biosynthetic fractionations in isoprenoids. Based on very negative $\delta \mathrm{D}$ values (down to $-317 \%$ ), 
and covariation with other markers for lignin, Grice et al (2009) tentatively interpreted this compound as deriving from a saprophytic algal pigment.

\subsection{Differences between lipids of marine algae and terrestrial plants.}

A common point of interest for the organic geochemist lies in distinguishing between marine versus terrestrial origins for organic matter, particularly when deposited in coastal marine sediments. As discussed in Section 3, at high latitudes meteoric water will be strongly depleted in D relative to seawater, leading to clear differences between the $\delta \mathrm{D}$ values of terrestrial versus marine products. In equatorial and temperate regions, where the isotopic contrast between environmental water and seawater is smaller, subtle differences in the characteristic fractionations of marine versus terrestrial plants must be taken into effect.

Sachse et al (2012) provide an exhaustive compilation of fractionation data relevant to terrestrial plants. In doing so, they compile the apparent (or 'net') fractionation between plant lipids and ambient environmental water, thus subsuming the effects of soil evaporation, leaf transpiration, and biosynthesis into a single fractionation (Fig 5). Their data show apparent differences between plant life forms (shrubs, trees, and grasses) and between physiologic groups (C3 vs $\mathrm{C} 4$ grasses). The median values of net fractionation for these groups range from $-150 \%$ (C3 grasses) to $-90 \%$ (shrubs). More recently, Gao et al (2014b) have suggested that such differences can be more readily understood in terms of phylogenetic lineages rather than growth form, with monocots exhibiting the largest fractionations (average near 170\%o) and eudicots and gymnosperms exhibiting smaller fractionations (near -100\%; Figure 6). Regardless of the origins of such signals, it is widely agreed that terrestrial plants fractionate $\mathrm{D} / \mathrm{H}$ less strongly (for n-alkyl lipids) than marine algae, typically by 20-70\%o (Sessions et al., 1999; Zhang and Sachs, 2007; Li et al., 2009). All else being equal then, this would lead to terrestrial organic matter being D-enriched relative to its marine counterpart.

When combined with the prevailing geographic distribution of isotope abundance in meteoric water, the following general patterns for organic $\mathrm{H}$ emerge. At low to moderate latitudes, precipitation is typically modestly D-depleted relative to seawater, and this is nearly counterbalanced by the smaller net fractionation of terrestrial plants to yield leafwax $\delta \mathrm{D}$ values that are virtually indistinguishable from marine products at -150 to -200\% (e.g., in Santa Barbara Basin, Li et al., 2011; and in Palau, Smittenberg et al., 2011). Less commonly, when evaporation is particularly intense (e.g., in northern Africa, Feakins, 2013; and in southwestern US, Hou et al., 2008) or where supplied water has a $\delta$ D value of 0\%o (e.g., salt marshes, Romero and Feakins, 2011) terrestrial leaf waxes can be modestly D-enriched relative to their marine counterparts, with typical $\delta \mathrm{D}$ values of -120 to $-150 \%$. Leaf waxes become noticeably D-depleted 
relative to marine lipids when the $\delta \mathrm{D}$ value of meteoric water drops below about $-70 \%$, yielding leaf waxes with $\delta \mathrm{D}<-200 \%$. In the modern Northern Hemisphere, this occurs roughly at latitudes of $40-50^{\circ}$ (see Fig 2).

\subsection{Differences between autotrophs and heterotrophs}

While most organic compounds in most sedimentary environments probably derive from photosynthetic algae and/or plants, in certain cases it is desirable to understand the isotopic characteristics of those derived from microbes, particularly heterotrophic bacteria but also (more rarely) chemoautotrophic bacteria and archaea. In these cases it is necessary to account for differences in the characteristic $\mathrm{D} / \mathrm{H}$ fractionations of these organisms. This is an area of active current research, and much remains uncertain. Nevertheless, existing data clearly show that large differences in isotopic fractionation are possible. For example, X. Zhang et al (2009) showed that two species of the soil bacterium Cupriavidus could fractionate $\mathrm{D} / \mathrm{H}$ in lipids relative to water by between $+200 \%$ and $-350 \%$ depending solely on their growth substrate. The mechanism driving these enormous changes appears not to be the isotopic composition of the substrates themselves, but rather changes in the metabolic pathways through which they are processed and reducing power is conserved. X. Zhang et al (2009) hypothesize that such D/H variations may originate in the enzymatic reduction of NADPH, although this remains unproven.

Regardless of the mechanistic causes, the resulting pattern of fractionation that emerges is as follows (Fig 7). Aerobic bacteria growing heterotrophically (i.e., by respiring organic substrates) tend to be D-enriched relative to plants and algae, and this pattern has been recently confirmed by Osburn et al (2013) and Heinzelmann et al (2015). Less certain is that bacteria growing chemoautotrophically (e.g., on $\mathrm{H}_{2}+\mathrm{CO}_{2}$ ) tend to be D-depleted (e.g. Valentine et al., 2004), although exceptions have already been observed (Campbell et al., 2009). In the former case, bacteria growing on sugars tend to exhibit fractionations of between -150 to $-50 \%$, whereas those growing on TCA-cycle intermediates like acetate and succinate tend to exhibit fractionations of between $-100 \%$ and $+200 \%$. Conversely, bacteria growing chemoautotrophically on $\mathrm{H}_{2} / \mathrm{CO}_{2}, \mathrm{H}_{2} / \mathrm{SO}_{4}$, and formate have exhibited fractionations of between -200 to $400 \%$, i.e. larger than those in plants. There is thus some overlap in ranges of fractionation between plants and bacteria. Moreover, some recent data (Osburn, 2013) have shown that anaerobic bacteria using nitrate exhibit similar patterns, but those using sulfate do not. There is thus ample evidence that this story is still unfolding, and there is likely quite a bit more complexity that is yet to be revealed.

Most of the work on this subject to date has been on cultures of single organisms. The obvious question is how ubiquitous the phenomenon is in the environment, but there is relatively little data available to answer it, because most environmental studies have focused on the products of plants and phytoplankton. 
Jones et al (2008), working on particulate organic matter in the SBB, showed that bacterial fatty acids, including odd chain-length and branched structures, were often D-enriched relative to those from phytoplankton by up to $100 \%$, but at least in one case (a cyclo-17:0 fatty acid) were hardly enriched at all. Li et al (2009) observed several bacterial fatty acids in SBB sediments, and while some of those (notably iso-14:0 and iso-15:0 fatty acids) were substantially D-enriched, others (anteiso-15:0, $n$-15:0, $n$-17:0) were not. Bacterial hopanols were D-enriched relative to eukaryotic sterols by an average of 65\%, albeit with substantial overlap in the distributions of these two compounds classes. Osburn et al (2011) reported data from bacterial mats growing in Yellowstone hot springs, and show that fatty acids from heterotrophic bacteria in the genus Thermus are D-enriched relative to those from cyanobacteria in the same mats by 25 to $100 \%$, whereas fatty acids from the chemoautotrophic Aquificales are D-depleted by $40-80 \%$. On the

other hand, lipids attributed to the photoheterotrophic Chloroflexus were only slightly D-enriched relative to those from cyanobacteria. Naraoka et al (2010) reported $\delta D$ values for fatty acids from hot spring microbial mats in Japan. They observed a $\mathrm{C}_{20: 1}$ fatty acid, attributed to a hydrogen-oxidizing chemoautotroph, with $\delta \mathrm{D}$ of $-469 \%$, but also a $\mathrm{C}_{16: 1}$ fatty acid attributed to a sulfur-oxidizing chemoautotroph with $\delta \mathrm{D}$ of only $-173 \%$. In summary, these limited field data do tend to support the general trends outlined above, while at the same time providing multiple exceptions to the rule.

\section{Preservation of the Signal: Isotopic exchange of ORganic H duRING diagenesis}

The combination of environmental water and biosynthetic fractionation sets the initial (or 'primary') isotopic composition of lipids that enter the sedimentary record. The next question is whether these $\delta \mathrm{D}$ values are preserved over geologic timescales? Several early studies based on bulk oil $\delta \mathrm{D}$ measurements claimed that $\mathrm{C}$-bound $\mathrm{H}$ is highly conservative, exhibiting little isotopic change over very long timescales (Yeh and Epstein, 1981; Schoell, 1984). There are, however, reasons to doubt the generality of this conclusion. Many diagenetic reactions involve the replacement, abstraction, or addition of $\mathrm{H}$, so we should expect $\mathrm{D} / \mathrm{H}$ exchange to at least be possible. Moreover, as we shall see shortly, there is now an abundance of evidence that isotopic exchange of C-bound-H does occur over geologic time. In considering this problem, there are two fundamental issues to grapple with: what are the mechanisms and rates of exchange, and what are the isotopic consequences of that exchange? At a more pragmatic level, we may also consider how we can recognize the occurrence (or lack) of isotopic exchange in ancient molecules, and what useful insight if any might be gained from ancient molecules that have undergone appreciable exchange. 


\subsection{Mechanisms and rates of $D / H$ exchange}

Many diagenetic reactions lead to the addition or removal of $\mathrm{H}$ in organic molecules (Fig 8), for example the dehydration of alcohols, saturation of double bonds, etc. The fractionations imparted by such reactions are difficult to predict a priori, and have not been studied extensively. Fortunately for the case of lipids they tend to affect only a small proportion of a molecule's hydrogen inventory, such that their net effect on the whole molecule $\delta \mathrm{D}$ value is minimal. For example the conversion of phytol to phytane involves the addition of just 3 out of 43 hydrogen atoms. Even if this reduction is accompanied by a 100\%o fractionation, it would change the $\delta \mathrm{D}$ value of the whole molecule by only $7 \%$. Other reactions, such as stereochemical inversion of a chiral center, lead to the replacement of one or more $\mathrm{H}$ atoms, but again these tend to affect a small number of positions. Moreover, the existence of such processes can be readily diagnosed because of the concomitant changes in molecular structure. Sessions et al (2004) and Schimmelmann et al (2006) provide more complete summaries of such processes. For our purposes here, the primary process of interest is what has been termed "pure exchange" (Sessions et al., 2004), i.e. the gradual replacement of $\mathrm{H}$ atoms at potentially every position in a molecule without any corresponding structural changes.

For hydrogen bonded to electronegative atoms like N, O, and S, pure exchange is extremely rapid in aqueous solution, typically reaching equilibrium in minutes to hours even at low temperature and neutral pH (Schimmelmann et al., 2006). Thus the D/H ratio of alcohol, carboxyl, thiol, amine, and other similar functional groups will solely reflect that of whatever water they last encountered, including in the laboratory. In contrast, $\mathrm{H}$ covalently bound to $\mathrm{C}$ is much more resistant to exchange. For example, the exchange half-time for an $n$-alkane in mineral-free water at $25^{\circ} \mathrm{C}$ and $\mathrm{pH} 7.0$ is greater than $10^{9}$ years (Koepp, 1978). For this reason alone, geochemists are commonly only interested in the isotope ratio of Cbound $\mathrm{H}$, and so have tended to focus their measurements almost entirely on lipids and hydrocarbons. Nevertheless, while the rate of exchange for C-bound $\mathrm{H}$ may be negligible in distilled water, increased temperature and mineral catalysis lead to appreciable rates in the natural environment.

There are presumably many different chemical mechanisms that could lead to D/H exchange of C-bound $\mathrm{H}$. Those that have received the most experimental attention involve the abstraction of $\mathrm{H}$ and stabilization of the resulting carbocation on acidic clay surfaces (Alexander et al., 1981, 1982, 1984). Others, particularly free-radical isomerization reactions during cracking reactions, must also play substantial roles (Leif and Simoneit, 2000). Minerals are known to play essential roles as catalysts, although very few studies have attempted to quantify this under natural environmental conditions. In general, clay minerals tend to exhibit greater catalytic activity towards $\mathrm{H}$ exchange than do other minerals, particularly 
carbonates (Alexander et al., 1982, 1984). The activity of water in sediments must also play a role, but to my knowledge no studies have yet addressed the issue of salinity in $\mathrm{D} / \mathrm{H}$ exchange.

Sessions et al (2004) summarized existing knowledge of the kinetics of D/H exchange during diagenesis, and concluded that relevant exchange rates [expressed as reaction half-times; $t_{1 / 2}=k / \ln (2)$ ] for aliphatic and aromatic hydrocarbons likely fall in the range of $10^{4}$ to $10^{8}$ years at temperatures of $50-100{ }^{\circ} \mathrm{C}$. This range is broad enough as to be nearly useless, and so is a subject that clearly requires further work. Practically the only firm conclusion is that the propensity of a particular molecular position to undergo $\mathrm{H}$ exchange is strongly correlated to the acidity of that position, thus aromatic and tertiary hydrogens exchange more rapidly than aliphatic methylene or methyl $\mathrm{H}$.

As a partial substitute for good experimental kinetic data, empirical data can provide a rough guideline as to the rate of $\mathrm{D} / \mathrm{H}$ exchange in typical environments. Radke et al (2005) studied the Permian Kupferschiefer and Jurassic Posidonienschiefer, both marine shales, and showed that in both cases $n$ alkane $\delta \mathrm{D}$ values were positively correlated with thermal maturity, i.e., higher maturity samples having higher $\mathrm{D} / \mathrm{H}$ ratios. Also, $\mathrm{D} / \mathrm{H}$ differences between phytane and $n$-alkanes that exist in immature samples disappear by moderate thermal maturity $\left(\mathrm{R}_{\mathrm{o}} \sim 1.3\right)$.

Pedentchouk et al (2006) studied isoprenoid and $n$-alkyl hydrocarbons in a 450m shallow marine core from the Gabon Basin. This core spans the transition from thermally immature to early mature sediments, and so provides a window into exchange during late diagenesis (Fig 9). Over this range of depths, the $\delta \mathrm{D}$ values of pristane and phytane change from $<-220 \%$ o to roughly $-120 \%$, a trend that is interpreted as reflecting $\mathrm{D} / \mathrm{H}$ exchange. $\delta \mathrm{D}$ values of $n-\mathrm{C}_{17}$ do not change over that same range, which the authors interpret as indicating a lack of isotopic exchange in that specific compound (and, by inference, other $n$ alkanes). Based on subsequent experimental data (see below), we now know that $n-\mathrm{C}_{17}$ is already close to isotopic equilibrium with porewaters, even at the shallowest depths. Thus it is impossible to be sure whether or not the $n$-alkanes are undergoing exchange in this particular case. Regardless, without a published thermal/subsidence model for these sediments we cannot calculate actual rate constants, even for pristane/phytane.

Dawson et al (2005) made similar observations for immature to mature sediments and crude oils from the Perth Basin in Western Australia, i.e. with pristane and phytane $\delta \mathrm{D}$ values distinct from those of $n$ alkanes in immature sediments, but similar in mature crude oils. They suggest clay-catalyzed exchange via a carbocation intermediate as the likely mechanism. These data again come from marine shales (Kokatea Fm), this time of Triassic Age. Dawson et al (2007) examined rocks of the late-Jurassic Vulcan sub-Basin (offshore Bonaparte Basin, NW Australia), and extended this pattern to a higher range of 
thermal maturity (Fig 10). The most remarkable features of their dataset are 1) catching the $n$-alkanes in the process of shifting to D-enrichment, and 2) showing that pristane/phytane eventually become Denriched relative to the $n$-alkanes. This would seem to be a definitive result, but for the fact that the $\delta \mathrm{D}$ values of pristane and phytane actually exceed the equilibrium fractionation with water (see Sect 5.2 below) in the most mature samples. Since this would be impossible to achieve via pure exchange, there is some question about exactly which process is driving the observed D-enrichments, and whether this may in part be due to kinetic fractionations during oil generation (Sect 6.1).

In addition to these studies of clay-rich marine sediments and shales, Xiong et al (2007) examined the $\mathrm{D} / \mathrm{H}$ ratios of $n$-alkanes preserved in Ordovician-aged carbonate rocks from the Bohai Bay Basin of eastern China. These rocks are highly mature, with equivalent $R_{o}$ values ranging from 1.8 to 2.3. Nevertheless, $n$-alkanes in these rocks preserve both a wide range of $\delta \mathrm{D}$ values (roughly -100 to $-180 \%$; see Sect 7.5), and in some cases large differences between odd/even homologous $n$-alkanes, both of which strongly suggest a lack of complete isotopic equilibration (although the occurrence of partial exchange cannot be ruled out). There is unfortunately not enough data to observe systematic trends with age or maturity, thus kinetic parameters cannot be estimated. Nevertheless, it is clear that $\mathrm{D} / \mathrm{H}$ exchange in this carbonate system must be slower than in the previously described shales. On the other hand, n-alkanes and isoprenoids from the Upper Devonian Duvernay Formation, an organic-rich carbonate source rock of the Western Canadian Sedimentary Basin, show clear evidence of isotopic exchange with increasing maturity, with nearly complete exchange indicated by an equivalent vitrinite reflectance (Ro) of $0.8 \%$ (Figure 11; Maslen et al., 2012). Thus isotopic exchange in carbonate rocks can sometimes be as rapid as in shales. The role of mineralogy in catalyzing hydrogen isotopic exchange is clearly ripe for further studies.

Dawson et al (2004) studied the $\delta D$ values of n-alkanes extracted from Permian to Cretaceous-aged torbanites, organic-rich lake sediments comprising organic matter that is dominantly derived from the freshwater alga Botryococcus braunii. Although the deposits do presumably contain clay minerals, they were all thermally immature as indicated by $\mathrm{C}_{31}$ hopane $22 S /(22 R+22 S)$ ratios of $0.37-0.55$. They studied 5 samples that ranged in paleo-latitude from tropical to arctic, and the resulting $\delta \mathrm{D}$ values clearly show the expected contrast in paleo-meteoric water isotopic composition (Figure 12). Although it is difficult to disprove the possibility of any $\mathrm{D} / \mathrm{H}$ exchange, the $\sim 80 \%$ contrast in $\delta \mathrm{D}$ is close to that seen in the modern, so it is unlikely that exchange has been extensive. This is the oldest example, as far as I am aware, of near-primary lipid $\delta \mathrm{D}$ signatures being preserved in sedimentary hydrocarbons.

In summary, there is now substantial evidence that hydrogen exchange processes become important during late diagenesis, and may have partially or largely erased primary (biosynthetic) signals by the time 
the oil window is reached. This suggests rate constants (half-times) of roughly $10^{4}-10^{5}$ years at temperatures of $80-100{ }^{\circ} \mathrm{C}$. One study of carbonate rocks has indicated much slower exchange than in shales, while a second study has indicated similar rates; the importance of clay mineral catalysis thus remains somewhat unsettled. In contrast, in sediments that remain cool $\left(<50-60{ }^{\circ} \mathrm{C}\right)$, primary signals can apparently be preserved for hundreds of millions of years even in clastic sediments.

\subsection{Equilibrium $D / H$ fractionations.}

The endpoint of D/H exchange should be isotopic equilibrium between C-bound $\mathrm{H}$ and $\mathrm{H}_{2} \mathrm{O}$ (and other exchangeable mineral-H reservoirs). At that point the $\delta \mathrm{D}$ values of the different species are not identical, but rather will be separated by the relevant (temperature-dependent) equilibrium fractionation factors. By analogy, carbonate $\delta^{18} \mathrm{O}$ and water $\delta^{18} \mathrm{O}$ are not identical, even when the carbonate precipitates in equilibrium with water. In the case of $\mathrm{H}$ isotopes though, the potential differences in $\delta \mathrm{D}$ values - even at equilibrium - are tens to hundreds of per mil (Sessions et al., 2004).

Measuring equilibrium fractionations in molecules that undergo exchange over million-year timescales is experimentally challenging. Using a combination of laboratory incubation experiments and ab initio molecular modeling, Wang et al (2009a, 2009b, 2013) have established a density functional theory (DFT) computational framework, anchored by experimental calibration, which allows us to predict equilibrium fractionation in linear, branched, and cyclic aliphatic hydrocarbons. Similar data are not yet available for aromatic compounds. Although there are a nearly infinite number of molecules and $\mathrm{H}$ positions of interest, fortunately the fractionation behavior of any given $\mathrm{H}$ atom is determined only by the few atoms closest to it. For example, the equilibrium fractionation of methyl $\mathrm{H}\left(\mathrm{R}-\mathrm{CH}_{3}\right)$ is largely independent of whether that methyl group is attached to a fatty acid, a hopanoid, or otherwise. Representative data, including temperature dependence of the fractionation, for linear alkanes can be found in Wang et al. (2009a), Table 1, and for cyclic alkanes in Wang et al. (2013), Table 4. Using these 'building block' reference values (Fig 13), it is possible to easily calculate the equilibrium D/H fractionation for any molecule by simply summing over all the hydrogen atoms in the molecule. For example, phytane has 18 primary H's attached to methyl groups $\left(\varepsilon_{1 / \mathrm{w}}\right.$ at $25^{\circ} \mathrm{C}=-141 \%$ ), 18 secondary (methylenic) H's with no methyl substituents $(\varepsilon=$ -75), 2 secondary H's with 1 methyl substituent $(\varepsilon=-66), 3$ tertiary H's with 1 methyl substituent $(\varepsilon=-8)$, and 1 tertiary $\mathrm{H}$ with 2 methyl substituents $(\varepsilon=+5)$. The weighted mean of these values is $-92.7 \%$, which is the expected $\mathrm{D} / \mathrm{H}$ fractionation between phytane and water at $25^{\circ} \mathrm{C}$.

Several interesting trends can be highlighted in these data. First, primary (methyl) H is strongly Ddepleted at equilibrium, tertiary $\mathrm{H}$ is moderately D-enriched, and secondary (methylenic) $\mathrm{H}$ is intermediate (Fig 13A). Coincidentally, when comparing linear (n-alkyl) and isoprenoid hydrocarbons, 
the increased content of (D-depleted) methyl $\mathrm{H}$ in isoprenoids is counterbalanced by a simultaneous increase in (D-enriched) tertiary $\mathrm{H}$, such that both classes of molecules tend to have very similar equilibrium fractionations, of around -70 to $-100 \%$. Isoprenoid structures should be slightly D-depleted, by about 10-20\%, a pattern that is commonly observed in petroleum samples ( $\mathrm{Li}$ et al., 2001; Sessions et al., 2004). Second, fractionation of primary H drops (becomes less D-depleted) with increasing temperature, whereas fractionation of tertiary $\mathrm{H}$ increases (becomes more D-depleted) and secondary $\mathrm{H}$ changes very little (Wang et al., 2009b). Again these trends counteract each other, such that both $n$ alkanes and isoprenoid hydrocarbons are predicted to have very little temperature dependence in their equilibrium fractionation (Fig 13A). This has not yet been experimentally confirmed, however. A corollary of this result is that the position-specific difference in $\delta \mathrm{D}$ between methyl and methylene positions, e.g. in propane, should be a very sensitive thermometer (Piasecki et al, 2015). Third, the presence of saturated cyclohexyl rings tends to shift organic $H$ to more positive $\delta D$ values by $10-20 \%$ for secondary H, and by 15-30\%o for tertiary H (Fig 13B; Wang et al., 2013). Thus napthenic compounds like decalin are predicted to be D-enriched relative to $n$-alkanes by $\sim 10 \%$ at equilibrium. Steranes and hopanes, with their large constituency of methyl H's, have predicted fractionations that largely overlap with those of $n$-alkanes, in rough agreement with data for hopanes from the Potiguar Basin (Ferreira et al., 2012).

\subsection{Diagnosing D/H exchange.}

The process of isotopic exchange presents a conundrum to the geochemist. Most importantly, the severity of $\mathrm{D} / \mathrm{H}$ exchange in sedimentary organic matter can vary from minimal at sea floor temperatures, to complete at temperatures of oil generation in marine shales. Thus, when confronted with hydrocarbon $\delta \mathrm{D}$ data from sediments, rocks, or oils, the first decision that must be made is whether to interpret the data in terms of environmental water and biologic fractionation, or equilibrium (thermal) fractionations, or both. Unfortunately, we are not yet able to make accurate predictions about the extent of D/H exchange based solely on time-temperature histories. In some cases where a large depth-sequence of data is available, the answer may be obvious as in Figs 9 and 10. In other cases, particularly for isolated samples, the appropriate interpretive framework will be less apparent. What is needed then is a means to quantify the relative extent of $\mathrm{D} / \mathrm{H}$ exchange experienced by any particular hydrocarbon sample.

A number of possible tests have been proposed. Comparing hydrocarbon $\delta \mathrm{D}$ values to those of modern environments is one simple possibility, but is of course difficult if the source is unknown. It is also fraught with problems related to subtle biologic differences when particular biomarker molecules are being considered. A related approach is to compare hydrocarbon $\delta \mathrm{D}$ values to those of porewaters, and 
see whether they are similar to predicted equilibrium fractionations. This is not foolproof, however, because under the right circumstances n-alkyl molecules can be biosynthesized with $\delta \mathrm{D}$ values already close to equilibrium with water (as in Fig 9). A third approach is to look for systematic differences in $\delta \mathrm{D}$ between different sedimentary horizons, under the assumption that such environmental signals will gradually disappear with increasing exchange (e.g., Pendentchouk et al., 2006). This has some merit when applied to bitumen extracts from intact stratigraphic sequences, but is obviously futile when applied to migrated and/or mixed hydrocarbons.

The best approach, first employed by Andersen et al (2001) and later elaborated by Sessions et al (2004), Dawson et al (2005, 2007), and Maslen et al (2012) seems to be comparison of coexisting isoprenoid and $n$-alkane molecules. As described in Section 4, phytol is biologically produced with a strong (typically 200\%) D-depletion relative to $n$-alkyl lipids (e.g., Fig 4), whereas both classes of molecules will have similar $\delta \mathrm{D}$ values at full isotopic equilibrium, regardless of temperature (Fig 13). Thus with increasing $\mathrm{D} / \mathrm{H}$ exchange, the difference in their $\delta \mathrm{D}$ values should diminish and eventually approach zero (Fig 14). This is true regardless of their starting isotopic compositions, the absolute rates of exchange, and which fluids and/or mineral phases they are exchanging with. Although the approach has now been applied in a number of academic studies (Andersen et al., 2001; Sessions et al., 2004; Schimmelmann et al, 2004; Dawson et al., 2005, 2007; Pendentchouk et al., 2005), it has not yet been quantified as a formal parameter suitable for use in models of hydrocarbon evolution. Note also that in at least one empirical study (Dawson et al., 2007; Fig 10) the pristane/n-alkane offset continued to change past the predicted offset, so this parameter may be somewhat compromised by kinetic fractionations.

Yet another approach, taken by Nabbefeld et al (2010a, 2010b) for their study of the Permian/Triassic boundary mass extinction, is to compare the temporal evolution of compound-specific $\delta \mathrm{D}$, kerogen $\delta \mathrm{D}$, and other isotopic proxies ( $\delta^{13} \mathrm{C}$ of organics and carbonates, $\delta^{34} \mathrm{~S}$ of pyrite). Nabbefeld et al (2010a) argue that changes in kerogen $\delta \mathrm{D}$ observed across the $\mathrm{P} / \mathrm{T}$ event are similar in different sections, and correlated with changes in $\delta^{13} \mathrm{C}$ and $\delta^{34} \mathrm{~S}$, and so must represent a preserved isotopic signal from the source organic matter. Shifts in $\delta \mathrm{D}$ are then interpreted as changes in the organisms producing organic matter. Nabbefeld et al (2010b) further argue that similar shifts are observed in compound-specific $\delta \mathrm{D}$ values, and should be similarly interpreted. This is in spite of the fact that the rocks are moderately thermally mature, and isoprenoid and n-alkyl carbon skeletons have similar $\delta \mathrm{D}$ values.

\section{FiNISHING TOUCHES: FRACTIONATING PROCESSES IN PETROLEUM SYSTEMS.}


In addition to H-exchange, a variety of other physical and chemical processes that occur in active petroleum systems can further influence hydrocarbon D/H ratios. Chief among these are the kinetic isotope effects accompanying primary and secondary cracking (oil generation), but also potentially include water washing, migration, evaporation/phase separation, biodegradation, and others. Although it is reasonable to assume that a fair amount of effort has been expended by industry examining such effects, there is very little published information. Most of the summary that follows is based on just a few studies.

\subsection{Kinetic fractionations during oil generation}

The process of oil formation involves thermal cleavage of C-C bonds, and to a lesser extent C-S and C-O bonds. Kinetic carbon isotope effects accompany such cleavage reactions, and lead to preferential breaking of ${ }^{12} \mathrm{C}-{ }^{12} \mathrm{C}$ bonds over ${ }^{12} \mathrm{C}-{ }^{13} \mathrm{C}$ bonds (Clayton, 1991; Tang et al., 2000). The products of these reactions (oil and gas) thus tend to be ${ }^{13} \mathrm{C}$-depleted, while the residual reactants (kerogen or oil) become ${ }^{13} \mathrm{C}$-enriched (e.g., Clayton and Bjoroy, 1994). An analogous phenomenon apparently exists for the case of $\mathrm{H}$ isotopes, even though it is not entirely apparent why this should be so (i.e., breaking a $\mathrm{C}-\mathrm{H}$ bond will surely have an isotope effect, but does not result in a smaller carbon skeleton). This phenomenon can be observed in related maturity series of oils (e.g., Santos Neto and Hayes, 1999; Li et al., 2001;

Schimmelmann et al., 2004; Dawson et al., 2005), where $\delta$ D values increase almost uniformly with thermal maturity. It is, however, difficult to disentangle the effects of equilibrium hydrogen exchange from those of kinetic cracking in these empirical studies.

The most useful constraints on kinetic D/H fractionations come from the combined heating experiments and $a b$ initio calculations of Tang et al (2005). They performed gold-tube pyrolysis experiments using a produced North Sea crude oil as feedstock, with heating at $10{ }^{\circ} \mathrm{C} / \mathrm{hr}$ up to $460{ }^{\circ} \mathrm{C}$. Anhydrous conditions were purposefully employed to eliminate the effects of D/H exchange with water. Their data show increases in $\delta \mathrm{D}$ values of up to $60 \%$ at $445{ }^{\circ} \mathrm{C}$ (equivalent $\mathrm{R}_{\mathrm{o}}=1.5$ ), and the effect is more pronounced for longer chain-length $n$-alkanes (Fig 15). The resulting correlation between $\delta \mathrm{D}$ values and alkane carbon number likely derives from a combination of two effects. The first is that longer-chain alkanes have higher rate constants for thermal cracking, and thus undergo more decomposition and more fractionation. The second is that the products of cracking tend to be D-depleted, and contribute more strongly to the inventory of short-chain compounds. The magnitude of this "isotope slope" has been suggested to be a potential maturity indicator suitable for high maturities (Tang et al., 2005), although tests of this hypothesis in real petroleum systems have not yet been reported.

Tang et al (2005) further showed that a simple kinetic model of oil cracking could qualitatively reproduce this pattern. Their model used an empirically derived distribution of activation energies for homolytic 
bond cleavage, combined with quantum chemical calculations of the change in entropy and enthalpy of $n$ octane upon isotopic substitution by $\mathrm{D}$ at varying molecular positions. The fit of model results to experimental data (not shown) is remarkably good at temperatures $<430{ }^{\circ} \mathrm{C}$, but the model under predicts fractionation at higher temperatures. The model also includes a "frequency factor ratio" that is tuned to provide greater accuracy. These limitations notwithstanding, the model can be used to predict $\mathrm{D} / \mathrm{H}$ fractionations under more realistic geologic heating rates $\left(1^{\circ} \mathrm{C} / \mathrm{Ma}\right)$. Tang et al predict that significant fractionations (due to kinetic isotope effects) should be expected only at relatively high maturity $\left(\mathrm{R}_{\mathrm{o}}>\right.$ 1.5; Fig 16).

\subsection{Fractionations during evaporation and condensation}

Just as for water, phase changes of liquid hydrocarbons will be accompanied by significant vapor pressure hydrogen isotope effects, and can lead to substantial fractionation. In contrast to water, where the vapor phase is D-depleted relative to liquid at equilibrium, for hydrocarbons the vapor phase is D-enriched relative to the liquid. This counterintuitive behavior is explained by the fact that the vapor pressure of polar molecules like water is dominated by hydrogen-bonding interactions between molecules, for which deuterium isotope effects are "normal". In contrast, the vapor pressure of hydrocarbons is determined primarily by Van der Waals interactions, and the strength of these interactions exhibits an "inverse" deuterium isotope effect (Hopfner, 1969). Thus in general we expect liquid hydrocarbons to become progressively D-depleted as they are evaporated. Conversely, gas-phase hydrocarbons should become progressively D-enriched as they are condensed.

These expectations are largely supported by the experimental study of Wang and Huang (2003), who progressively evaporated and measured a suite of organic solvents, including $n$-alkanes, BTEX aromatic compounds, and simple alcohols. Hydrocarbons were characterized by positive evaporative fractionations (i.e., vapor phase D-enriched relative to liquid) of between 3 and 34\%, whereas methanol and ethanol gave fractionations of -41 and $-29 \%$, respectively. No field data on naturally evaporated (or condensed) oil samples have yet been reported.

\subsection{Fractionations during biodegradation}

Given the very large intrinsic isotope effects associated with many enzymatic reactions, there has been some interest in the possibility of large $\mathrm{D} / \mathrm{H}$ fractionations characterizing specific biodegradation pathways. For example, the first rate-limiting step in microbial oxidation of hydrocarbons generally involves breaking a C-H bond to add a functional group (Heider, 2007), and could plausibly lead to isotopic fractionation of the residual hydrocarbon pool. However, such hopes have not thus far generally materialized, although modest fractionations due to biodegradation are widely observed. Pond et al (2002) 
studied the aerobic bacterial oxidation of $n$-alkanes in batch cultures, and measured intrinsic fractionation factors ranging from zero for long-chain $n$-alkanes to a maximum of $-19 \%$ for $n$ - $\mathrm{C}_{16}$, with residual alkanes becoming progressively $\mathrm{D}$-enriched. Ward et al (2000) measured fractionations during the anaerobic degradation of toluene by a mixed methanogenic consortium, and found increases in $\delta \mathrm{D}$ values of up to $60 \%$ at $>95 \%$ degradation. They noted that their data do not readily conform to a standard Rayleigh-distillation type model, and instead inferred the existence of two distinct fractionations, of -69\%o and $-12 \%$, corresponding to two different phases of culture growth. Hunkeler et al (2001) measured the aerobic degradation of benzene by strains of Acinetobacter and Burkholderia, and measured intrinsic D/H fractionations of $-12.8 \%$ and $-11.2 \%$, respectively. Gray et al (2002) measured the aerobic degradation of methyl $t$-butyl ether (MTBE) in both pure culture and from a field degradation experiment, and derived fractionation factors ranging from $-29 \%$ to $-66 \%$. Mancini et al (2003) studied the degradation of benzene by anaerobic enrichment cultures using nitrate, sulfate, or $\mathrm{CO}_{2}$ as terminal electron acceptor, and found fractionations ranging between -29 to $-79 \%$. Kuder et al (2005) examined the biodegradation of MTBE by an anaerobic enrichment culture, and measured an intrinsic fractionation of $-16 \%$.

Data from at least two field studies of petroleum are available for comparison with these experimental data. Sun et al. (2005) studied a suite of 7 oils, all derived from the lacustrine Shahejie Fm of the Liaohe Basin in NE China and varying systematically in their level of biodegradation from none to "heavy". The most biodegraded oils in this sequence experienced nearly complete loss of $n$-alkanes, representing $>95 \%$ removal. $n$-Alkane $\delta \mathrm{D}$ values increase from roughly $-175 \%$ to $-140 \%$ across this range of biodegradation levels, consistent with the available laboratory studies in suggesting a relatively small fractionation. Asif et al (2009) studied a series of "lightly" biodegraded oils from the Upper Indus Basin of Pakistan. They showed that low-molecular weight $n$-alkanes $\left(\mathrm{C}_{14}-\mathrm{C}_{22}\right)$ exhibit the largest D-enrichment of up to 50\%o upon biodegradation, high-MW $n$-alkanes $\left(>\mathrm{C}_{23}\right)$ exhibit a smaller D-enrichment ( $\sim 20 \%$ on average), and pristane and phytane show virtually no isotopic changes. As a result, the difference in $\delta \mathrm{D}$ values between pristane/phytane and LMW n-alkanes increased with increasing biodegradation (Fig 17).

Several authors (e.g., Ward et al, 2000; Mancini et al, 2003) have commented that the changes in $\delta$ D observed at the molecular level during biodegradation make this a potentially useful tool for quantifying biologic degradation of hydrocarbons. Although this is likely true in the case of bioremediation of petroleum-contaminated soils where the source composition is well defined (Mancini et al., 2002), it is unlikely to be true in deeply buried rocks and petroleum reservoirs. This is primarily because the shift toward D-enrichment caused by biodegradation is in the same direction as many other processes, notably $\mathrm{H}$ exchange and thermal maturation, making them difficult to deconvolve. In contrast, the increasing difference in $\delta \mathrm{D}$ between $n$-alkyl and isoprenoid hydrocarbons noted by Asif et al (2009) is in the 
opposite direction of that expected from $\mathrm{H}$ exchange and maturation, and so may be more useful in this context.

\subsection{Fractionations caused by adsorption, migration, and water washing.}

In theory, equilibrium isotope effects between liquid, surface-adsorbed, and aqueous (dissolved) hydrocarbons could lead to $\mathrm{D} / \mathrm{H}$ fractionation of oils as they migrate through the subsurface ("geochromatography") and/or undergo water-washing. However, DFT calculations suggest that such effects are likely to be quite small because the strength of intermolecular interactions between nonpolar hydrocarbons and polar mineral surfaces and/or water is very weak (Ying Wang, unpublished data). There are not, to my knowledge, any published experimental data attempting to specifically measure the magnitude of these isotope effects.

Li et al (2001), in their study of oils from the Western Canadian Sedimentary Basin, considered two oils thought to be derived from the same source but having migrated very different distances. The Pembina and Joarcim fields, both in Alberta, are both inferred to be sourced from the Second White Speckled Shales of the upper Cretaceous. However, whereas the Pembina field is located quite close to the source kitchen, a migration distance of $>150 \mathrm{~km}$ is inferred for the Joarcim field (Larter et al, 1996). The $\delta \mathrm{D}$ values of $n$-alkanes from these two oils differed by less than 4\%, implying a negligible fractionation during migration. However, because very low $(<100 x)$ contact volumes of water are inferred based on hexane/benzene ratios, little can be concluded about the possible effects of water-washing.

\section{Selected CASE STUdies}

Of the four first-order controls on hydrocarbon deuterium content discussed above, the first two (composition of environmental water, and biologic fractionations) clearly control the $\delta \mathrm{D}$ values of lipids in immature sediments. In thermally overmature rocks, it is nearly certain that these environmental signatures will be entirely overprinted by those of the second two processes, namely hydrogen exchange and oil generation. In between - rocks and sediments of modest thermal maturity, a category that is of primary interest to organic geochemists - it is hard to predict a priori which of these processes will predominate. We therefore turn next to empirical data from several petroleum basins around the world, seeking an answer to this question.

\subsection{Potiguar Basin, Brazil}

Santos Neto and colleagues $(1996,1998,1999)$ provided some of the first detailed D/H studies of a petroleum system, the onshore Potiguar Basin of northeast Brazil. Working before the advent of 
compound-specific methodology, they presented "bulk" $\delta \mathrm{D}$ data for saturate fractions, which can nevertheless be interpreted as representing approximately the mean composition of $n$-alkanes. Their studies encompass both source rock extracts and oils, ranging in age from the early Cretaceous (Necomian) Pendencia Fm through the mid-Cretaceous (Aptian) Alagamar Fm. The former was deposited primarily under low-latitude lacustrine conditions, whereas the latter is considered to be open to evaporitic marine conditions. Both were deposited at low latitudes, so intense evaporation and meteoric waters with $\delta \mathrm{D}>0 \%$ are to be expected based on paleogeography.

Perhaps the most significant finding of these studies was the greater $\delta \mathrm{D}$ values of extracts from lacustrine facies rocks relative to the marine/evaporitic rocks (Fig 18). Lacustrine shales of the Pendencia Fm yield saturate fractions with $\delta \mathrm{D}$ values of -100 to $-130 \%$, and oils with $\delta \mathrm{D}$ values of -85 to $-100 \%$. In contrast, marine shales and carbonates of the Alagamar Fm yield extractable saturate fractions with $\delta \mathrm{D}$ values of typically -130 to $-160 \%$, and oils with $\delta \mathrm{D}$ values of -115 to $-125 \%$. Rocks of the lowermost Alagamar constitute the sole exception to this pattern, yielding saturate fraction $\delta \mathrm{D}$ values of -110 and $-116 \%$ that fall midway between the two endmembers. The authors interpret these data as representing a shift in the $\delta \mathrm{D}$ values of environmental water, from up to $50 \% \mathrm{D}$-enriched during the evaporative lacustrine facies, to typical seawater $\delta \mathrm{D}$ of $0 \%$ in the later marine facies. It is notable that such significant $\delta \mathrm{D}$ differences can be preserved in rocks of low to moderate thermal maturity that are at least $150 \mathrm{Ma}$ old.

$\delta \mathrm{D}$ values of saturate fractions from oils were observed to be $\mathrm{D}$-enriched relative to those from source rocks by typically 15-30\%. This constitutes one of very few (published) direct comparisons between source rocks and produced oils, so it is difficult to say whether the offset is typical. Nevertheless, it is in the direction expected based on both $\mathrm{H}$-exchange processes and kinetic fractionations during oil generation. Santos Neto and Hayes (1999) observed no consistent trend in saturate $\delta \mathrm{D}$ with thermal maturity, although the range of maturities covered was relatively small. Finally, Santos Neto and Hayes (1999) compared Potiguar oils with the same source but differing in level of biodegradation or in migration distance, and concluded that neither had a significant impact on saturate fraction $\delta \mathrm{D}$.

More recently, Ferreira et al (2012) examined the H-isotopic compositions of hopanes, tricyclic- and tetracyclic terpanes isolated from Potiguar Basin rock extracts and oils, all derived from the lacustrine facies of the Pendencia Fm, together with associated formation waters (Fig 19). This is the only study thus far to report $\mathrm{D} / \mathrm{H}$ data for cyclic terpanes in rocks and oils, presumably because of the difficulty in obtaining cleanly resolved chromatographic peaks.

These studies show that hopanes in both rock extracts and related oils have $\delta \mathrm{D}$ values in the range of -100 to $-130 \%$, are similar to each other and to $n$-alkanes from related rocks (see Fig 18), and are near the 
predicted isotopic equilibrium with coeval formation waters having $\delta \mathrm{D}$ values of -20 to $-30 \%$. All of these pieces of evidence suggest molecules that have undergone appreciable $\mathrm{D} / \mathrm{H}$ exchange. At the same time, however, tri- and tetracyclic terpanes have $\delta \mathrm{D}$ values that are more $\mathrm{D}$-depleted than hopanes by $\sim 45 \%$ in oils, and $\sim 80 \%$ in rock extracts. These molecules are demonstrably not in isotopic equilibrium with formation waters or even with hopanes, and presumably retain more D-depleted compositions as a result of their (as yet unknown) biotic origins. Given the similarities in structure between the tri- and tetracyclic terpanes, it is tempting to infer that the hopanes have not fully exchanged either, and so must have been biosynthesized with relatively D-enriched compositions, perhaps as a result of heterotrophic bacterial metabolism (see Section 4.3).

\subsection{Western Canadian Basin}

In the first study of a petroleum system to employ compound-specific D/H methodology, Li et al (2001) measured $n$-alkanes in oils from a variety of Paleozoic and Mesozoic source rocks in the Western Canadian Sedimentary Basin. Their data show a number of trends that have proven to be quite typical of dominantly marine-sourced oils (Fig 20). First, all of the studied oils exhibited trends of increasing $\delta D$ value with increasing $n$-alkane chain length, an "isotope slope" that can now be attributed to kinetic fractionations during oil generation (Tang et al., 2005). Second, most of the oils have $\delta D$ values that fall in the range of $-80 \%$ to $-140 \%$, which are typical for marine source rocks. At the time, the equilibrium $\mathrm{D} / \mathrm{H}$ fractionations for hydrocarbons were unknown, and so $\mathrm{Li}$ et al (2001) interpreted these values as being quite close to a "primary" biosynthetic fractionation of $-150 \%$, (Section 4 ), thus representing only small amounts of exchange. In hindsight, we now know that this range is entirely consistent with equilibrium $\mathrm{D} / \mathrm{H}$ fractionations between water and $n$-alkanes (Section 5.2).

Several oils possess $\delta \mathrm{D}$ values significantly outside this typical range. Two oils tentatively attributed to Cambrian lacustrine source rocks have $\delta \mathrm{D}$ values centered around -170\% (Figure 20, bottom panel), which was interpreted as representing D-depletion of environmental (lake) water at the time of source deposition. Two oils from the Upper Cretaceous Second White Speckled Shale, a marine source rock, have even more negative $\delta \mathrm{D}$ values centered around $-180 \%$, which are harder to explain. Li et al (2001) attribute them to a restricted marine setting in which discharge of a large, high-latitude river significantly lowered the $\delta \mathrm{D}$ of local seawater (by up to $80 \%$ ), a scenario that has no modern analog. Two oils derived from the Devonian Keg River Fm, a carbonate/shale unit exhibiting evaporitic facies, exhibit slightly Denriched compositions centered around -90\% (Fig 20, top panel). These values are interpreted as reflecting a modest $\mathrm{D}$-enrichment of environmental water during deposition of the source rocks under evaporitic conditions. 
Questions about source composition notwithstanding, these oils are all in contact with formation waters having similar $\delta \mathrm{D}$ values today, and so have clearly not undergone complete $\mathrm{D} / \mathrm{H}$ exchange with modern formation waters. Either the original D/H differences were larger than those that appear today, and the oils have undergone only partial exchange, or else exchange during petroleum generation has been more pervasive but the exchanging reservoir is not modern formation water (see discussion in Section 5.4).

A second important result from Li et al (2001) lies in definitively showing a trend of increasing $\delta \mathrm{D}$ with maturity that nicely compliments the experimental predictions of Tang et al (2005). By comparing oils of varying maturity derived from the same source, they were able to show increases in $\delta \mathrm{D}$ of up to $40 \%$ associated with maturation (Fig 21). It is unclear whether these shifts are caused by increasing D/H exchange, kinetic fractionations during cracking, or both. But in any case, the pattern is quite typical.

\subsection{Eastern Australian terrestrial basins}

Schimmelmann et al (2004) studied the $\delta \mathrm{D}$ and $\delta^{13} \mathrm{C}$ values of both individual $n$-alkanes and bulk kerogen, oils, and oil fractions produced from the Cooper-Eromanga, Gippsland, and Otway basins of eastern Australia. These basins are all dominantly sourced from Permian to Cretaceous aged terrestrial sediments, and so provided an initial foray into isotopic variability in terrestrial organic matter. While much of the resulting data is used to interpret specific oil-source correlations, three more general principles can be recognized. First, the weighted-mean $\delta \mathrm{D}$ values of individual $n$-alkanes were - in virtually all cases nearly identical to bulk oil $\delta \mathrm{D}$ values. This observation strongly supports the use of compound-specific $\delta \mathrm{D}$ data in quantitative source-apportionment calculations.

The second observation is that in all cases, the $\delta \mathrm{D}$ values of isoprenoid alkanes (i.e., pristane and phytane) were highly similar to those of $n$-alkanes. As discussed in Section 5.3, the disappearance of primary biosynthetic differences in $\delta \mathrm{D}$ between these classes of lipids makes a strong case for nearly complete isotopic exchange of hydrogen in these molecules over time. Patterns of increasing $\delta \mathrm{D}$ with carbon number do exist, as in virtually every other oil that has been examined, so there are clearly overprints of kinetic fractionations arising during oil generation.

The third observation, seemingly at odds with the second, is that these terrestrially-sourced oils preserve a huge range of isotopic compositions. This is most apparent in the Otway Basin, where where oils sourced from lacustrine algal facies of the early Cretaceous Crayfish Group have $\delta \mathrm{D}$ values near $-100 \%$, whereas those sourced in coaly facies of the Crayfish Group, and terrestrial sediments of the Eumarella Fm, have $\delta$ D values that approach $-230 \%$ (Fig 22). Schimmelmann et al (2004) point out that the pattern of isotopic depletion follows both a geographic and temporal pattern, but that modern formation waters exhibit no 
such trend. Moreover, whole-rock kerogen isolates from this basin exhibit similar trends, in some cases changing by $100 \%$ or more within a few hundred meters in the same core, so it cannot simply be one of maturity. The trend thus almost certainly reflects a gradient in $\delta \mathrm{D}$ values of original sedimentary organic matter, which in turn reflects changing meteoric water composition as Australia split from Antarctica in the late Cretaceous.

Observations 2 and 3, above, as well as similar ones for Permian/Triassic sequences (Nabbefeld et al., 2010a, 2010b) lie at the heart of current confusion over the nature of hydrocarbon $\mathrm{D} / \mathrm{H}$ exchange in sedimentary sequences (see review by Schimmelmann et al., 2006). How can D/H exchange erase all signs of biosynthetic fractionations in the original lipids, while at the same time preserving original source signals in the bulk hydrocarbons? Although the answer is far from settled, a working hypothesis is that modern formation waters do not represent the primary reservoir of hydrogen that is exchanging with hydrocarbons. Rather, isotopic exchange might primarily involve hydrogen from ancient waters trapped in source rock pores, mineral-bound hydrogen such as that in clays, and/or organic hydrogen itself. Homogenization of hydrogen between and amongst organic compounds during petroleum generation, but with little incorporation of formation water hydrogen, is perhaps the simplest explanation.

\subsection{Bohai Bay Basin, NE China}

Several studies have examined the $\mathrm{D} / \mathrm{H}$ ratios of hydrocarbons from source rocks and oils of the Bohai Bay Basin in northeast China. Xiong et al (2005) worked on Eocene-aged source rocks of the Shahejie Fm, Liaohe subbasin, which include terrestrial organic matter in depositional facies that vary from closed hypersaline lacustrine to freshwater paralic. All of these sources yield $n$-alkanes that are moderately Ddepleted relative to more typical marine sources, and the two can be distinguished from each other by a further D-depletion of about $40 \%$ in the freshwater facies (Fig 23). This difference presumably reflects

original differences in the $\mathrm{D} / \mathrm{H}$ ratio of environmental water. $\delta \mathrm{D}$ values approaching $-200 \%$ or $n$-alkanes from the hypersaline lacustrine source are a stern reminder that not all evaporitic systems will yield relatively D-enriched organic matter. Several of the oils from this basin, and elsewhere, exhibit patterns of $\delta \mathrm{D}$ versus carbon number that are decidedly nonlinear, with curves, dips, and peaks all apparent. Explanations for such patterns have not yet been provided, but they presumably contain useful information about the petroleum system, such as mixing of sources. Researchers are thus strongly encouraged to collect $\delta \mathrm{D}$ profiles for the complete series of $n$-alkanes, and not rely on just a few selected compounds to define linear trends.

Tuo et al (2006) also studied 5 source rock samples from the Shahejie Fm of the Liaohe subbasin, and recorded similar ranges of $\delta \mathrm{D}$ values for $n$-alkanes. This study further measured pristane, phytane, and 
several diterpenoid hydrocarbons in the same samples. Both pristane and phytane are D-depleted relative to the $n$-alkanes (not shown), indicating low thermal maturity and incomplete $\mathrm{D} / \mathrm{H}$ exchange, and pristane is consistently D-depleted relative to phytane by $30-40 \%$, which is unusual. The authors interpret this difference as evidence that pristane and phytane are - in these samples at least - derived from different source molecules and/or organisms, rather than coming from the same phytol source. Perhaps more interesting, the $\delta \mathrm{D}$ values of 5 separate diterpanes are highly consistent between oils, but highly variable between compounds (Fig 24). Whereas pimarane and norpimarane have $\delta \mathrm{D}$ values that are typically -270 to $-320 \%$, simonellite and dehydroabietane have values that are typically -150 to $-200 \%$. The authors attribute the isotopic differences to differing biosynthetic fractionations. While this may yet turn out to be correct, such large differences among similar isoprenoid lipids have not yet been observed in any modern organisms, particularly plants.

Liu et al (2006) studied Paleozoic source rocks and oils of the Huanghua subbasin of the Bohai Bay basin. They observed a remarkably narrow range of $\delta \mathrm{D}$ values, which allowed them to differentiate between lower (-110 to $-140 \%$ ) and upper (-130 to $-160 \%$ ) Paleozoic sources (Fig 25). The difference is attributed to the presence of terrestrial coal beds in the Upper Paleozoic source rocks, presumably reflecting increased D-depletion of terrestrial meteoric waters. However, this pattern of depletion, as well as the greater slope of $\delta \mathrm{D}$ versus carbon number for the lower Paleozoic, could also be explained by higher levels of thermal maturity and $\mathrm{D} / \mathrm{H}$ exchange in the older rocks.

Xiong et al (2007) studied Ordovician-aged carbonate source rocks from the Jiyang subbasin of the Bohai Bay basin. In contrast to the very narrow $\delta \mathrm{D}$ distributions in the nearby Huanghua subbasin (Fig 25), in the Jiyang subbasin extractable $n$-alkanes exhibit a relatively wide range of $\delta \mathrm{D}$ values, from -100 to 170\% (Fig 26, left panel). This range is interpreted to reflect mainly differing contributions of marine and terrestrial organic matter, a point that is at least partially backed up by biomarker distribution patterns. The most remarkable aspect of this spread is that it persists in $~ 450$ Ma rocks with high thermal maturity ( $\mathrm{R}_{\mathrm{c}}$ up to 2.3 based on methyl-phenanthrene index), suggesting relatively little $\mathrm{D} / \mathrm{H}$ exchange. As discussed above (Sect 5.1), this is perhaps due to the lack of catalytic clay minerals in these carbonate rocks, but could theoretically also reflect limited access of formation water to carbonate-occluded organic matter. Even more impressive is the organic matter released by dissolution of the carbonate matrix (Fig 26 , right panel). In some samples, there is an $80 \%$ difference in $\delta \mathrm{D}$ values preserved between even- and odd-numbered $n$-alkanes, with the even numbers being $\mathrm{D}$-enriched. The origins of such a pattern are unknown, but presumably reflect differing biotic sources for the even versus odd compounds. They might also reflect mixing between two different sources with different isotopic compositions. But in any case, the preservation of this pattern is a clear indication of minimal isotopic exchange in spite of very high 
thermal maturity. The odd/even pattern is also a potentially valuable source correlation tool, as it only occurs in select samples.

\section{SUMMARY}

Four general controls on the $\mathrm{D} / \mathrm{H}$ ratios of hydrocarbons can be recognized, and all may important roles in different geologic settings. Environmental water serves as the common starting point for all organic hydrogen, and seawater $\delta \mathrm{D}$ values are nearly homogenous in both space and time. Fractionations imparted by the hydrologic cycle will be most visible as D-enrichments in low-latitude strongly evaporative lakes and basins, and as D-depletions in high-latitude or continental interior environments. In the modern world, $45^{\circ}$ latitude is a rough cutoff above which the latter effects might become easily recognized.

Biosynthesis of lipids by biota imparts a large fractionation, resulting in the ubiquitous D-depletion of organic $\mathrm{H}$ relative to environmental water. This fractionation is relatively constant in plants, and $-170 \%$ is suggested as a typical value for $n$-alkyl lipids in marine phytoplankton. Somewhat smaller fractionations, typically -100 to $-150 \%$, are observed in terrestrial plants as a result mainly of leafwater transpiration. Fractionations by heterotrophs are generally observed to be smaller than those of plants, resulting in less negative $\delta \mathrm{D}$ values, while those by chemoautotrophs tend to be larger and produce more negative $\delta \mathrm{D}$ values, although numerous exceptions to this pattern have already been recognized. Isoprenoid lipids are virtually always strongly D-depleted relative to their n-alkyl counterparts, with sterols and hopanols having typical $\delta \mathrm{D}$ values near $-270 \%$, and phytol being $-350 \%$ or lighter.

Over geologic timescales, isotopic exchange of C-bound $\mathrm{H}$ occurs to varying extents, and at varying rates, leading to changes in isotopic composition (generally D-enrichment). The clearest way to recognize such exchange is via comparison of coeval $n$-alkyl and isoprenoid hydrocarbons, which are biosynthesized with widely divergent $\delta \mathrm{D}$ values. In marine shales, isotopic exchange has generally erased such biosynthetic offsets by the start of oil generation, whereas limited evidence suggests that such processes are much slower in carbonate rocks lacking the catalytic activity of clay minerals. Hydrogen exchange leads to hydrocarbon $\delta \mathrm{D}$ values that - at equilibrium - are D-depleted relative to water by 80 to $120 \%$, largely irrespective of temperature and n-alkyl versus isoprenoid structure. An outstanding question remains, however, as to which reservoir of $\mathrm{H}$ is relevant to this exchange process. Limited evidence suggests that organic and/or mineral $\mathrm{H}$ in the source rocks, rather than formation water, is of primary importance.

Generation of hydrocarbons via thermal cracking induces kinetic fractionations that lead to further Denrichment and, typically, an 'isotope slope' in which $\delta \mathrm{D}$ values increase with carbon number. Because 
such processes shift $\delta \mathrm{D}$ values in the same direction as $\mathrm{H}$-exchange, they can be hard to definitively recognize via absolute shifts in $\delta \mathrm{D}$ values, and are likely noticeable only at higher levels of maturity. Changes in isotope slope appear more promising as a means to identify kinetic processes. Evaporation and biodegradation both lead to subtle (tens of \%o) increases in $\delta \mathrm{D}$ of $\mathrm{n}$-alkanes that will be difficult to recognize in petroleum systems. Migration and water washing probably have little impact on hydrocarbon $\delta \mathrm{D}$ values.

The occurrence of these multiple, overlapping processes mean that sedimentary hydrocarbon $\delta \mathrm{D}$ values are substantially non-unique, often recording a mixture of environmental, biologic, and diagenetic signals. Although complex, we now know enough about the relevant processes - with the possible exception of exchange kinetics - to attempt to deconvolve these multiple influences. Perhaps the biggest opportunities left untapped relate to quantitative modeling of $\delta \mathrm{D}$ values in partially-exchanged molecules, which could potentially be used to extract biologic or paleoenvironmental information from thermally mature rocks, to constrain thermal history models if the kinetics of exchange can be independently constrained, or to use the competing equilibrium-exchange and kinetic-cracking fractionations to understand the timing and duration of hydrocarbon generation and migration.

Acknowledgements. I thank the many colleagues and friends who have helped me contribute to studies of hydrogen isotopes in petroleum systems over the years, including Arndt Schimmelmann, Roger Summons, Olaf Podlaha, John Hayes, Eugenio Santos Neto, Ying Wang, Alexandre Ferreira, and Wanglu Jia. Thanks to Kliti Grice and an anonymous reviewer who provided valuable comments on the manuscript, and to Darius Strapoc and Erdem Idiz who handled the editorial duties. An earlier version of this manuscript was supported by Royal Dutch Shell; support was also provided by National Science Foundation award \#EAR-1529120 to ALS. 


\section{Figure Captions}

Figure 1. Evolution of the isotopic composition of cloud water vapor and precipitation as the air mass cools. After Clark and Fritz (1997), recalculated for $\delta D$ using fractionation factors from Merlivat and Nief (1967) and Majoube (1971).

Figure 2. The global pattern of mean annual precipitation $\delta \mathrm{D}$ values. Downloaded from waterisotopes.org with the scale redrawn.

Figure 3. Compilation of net $\mathrm{D} / \mathrm{H}$ fractionations between $n-\mathrm{C}_{29}$ alkane leaf waxes of individual plants and mean annual precipitation, as a function of either relative humidity (left) or annual evapotranspiration (right). Both show a decrease in fractionation of about 50-60\%o under more arid conditions attributable at least in part to leaf water transpiration. Redrawn from Sachse et al (2012).

Figure 4. Histograms of $\delta \mathrm{D}$ values for 1186 lipid compounds measured in a 2-m sediment core from Santa Barbara Basin. The bimodal distribution of $\delta \mathrm{D}$ values reflects the primary biosynthetic differences between lipids with $n$-alkyl and isoprenoid carbon skeletons. Redrawn from Li et al (2009).

Figure 5. Summary of net $\mathrm{D} / \mathrm{H}$ fractionations between $n-\mathrm{C}_{29}$ leafwax alkane and mean annual precipitation for terrestrial plants grouped by growth form. Redrawn from Sachse et al (2012).

Figure 6. Summary of net $\mathrm{D} / \mathrm{H}$ fractionations between leaf wax lipids $\left(\mathrm{C}_{29} n\right.$-alkane or $\mathrm{C}_{28} n$-acid $)$ and mean annual precipitation for terrestrial plants grouped by phylogeny. Redrawn from Gao et al (2014). Figure 7. Cartoon from Valentine (2009) illustrating the idea that groups of microbes utilizing different metabolic pathways will produce lipids with differing characteristic ranges of $\delta \mathrm{D}$ values. Although this "rule" still seems to work more often than not, many exceptions to it have already been found.

Figure 8. Examples of chemical reactions potentially leading to changes in D/H ratios. (1) pure exchange, (2) stereochemical inversion, (3) rearrangement, (4) hydrogen addition, (5) hydrogen loss. Hydrogen positions affected by each reaction are shown on the product. Redrawn from Sessions et al. (2004).

Figure 9. $\delta \mathrm{D}$ values of $n-\mathrm{C}_{17}$ alkane, pristane, and phytane in a sediment core from Gabon Basin spanning a range of thermal maturity as indicated by the $20 S /(R+S)$ sterane ratio. The changing $\delta \mathrm{D}$ values for pristane and phytane are interpreted as resulting from $\mathrm{H}$-isotopic exchange. Redrawn from Pedentchouk et al. (2006).

Figure 10. Changes in $\delta \mathrm{D}$ values of $n$-alkanes, pristane, and phytane from sediments of the Vulcan Basin, Paqualin-1 well, as a function of depth. Redrawn from Dawson et al (2007). 
Figure 11. Changes in $\delta \mathrm{D}$ values of $n$-alkanes, pristane and phytane as a function of thermal maturity from carbonate rocks of the Upper Devonian Duvernay Formation. Redrawn from Maslen et al (2012).

Figure 12. $\delta \mathrm{D}$ values of $n$-alkanes extracted from torbanite deposits of varying paleo-latitude (as indicated by labels on graph). Redrawn from Dawson et al. (2004).

Figure 13. Predicted equilibrium $\mathrm{D} / \mathrm{H}$ fractionations between water and organic $\mathrm{H}$ in linear (panel $\mathrm{A}$ ) or cyclic (panel B) alkanes as a function of temperature. Note the expanded vertical scale in panel B. Redrawn from Wang et al. (2009b) and (2013).

Figure 14. $\delta \mathrm{D}$ values of $n$-alkanes, pristane and phytane in four Perth Basin cores of varying thermal maturity. The offset in $\delta \mathrm{D}$ between isoprenoids and $n$-alkanes decreases with increasing thermal maturity. At the highest maturities, there is also a shift upward in $n$-alkane $\delta \mathrm{D}$ values. Redrawn from Dawson et al. (2005).

Figure 15. $\delta \mathrm{D}$ values of $n$-alkanes in a crude oil subjected to closed-system, anhydrous pyrolysis at a heating rate of $10{ }^{\circ} \mathrm{C} / \mathrm{hr}$. Listed temperatures refer to the maximum temperature at which a sample was recovered. The increase in $\delta \mathrm{D}$ values with maturity is interpreted to reflect mainly kinetic isotope effects associated with homolytic bond cleavage during oil cracking. Redrawn from Tang et al (2005).

Figure 16. Calculated changes in $\delta^{13} \mathrm{C}$ (blue) and $\delta \mathrm{D}$ (orange) values for $n$-icosane as a function of temperature with a heating rate of $1{ }^{\circ} \mathrm{C} \mathrm{Ma}^{-1}$. For reference, the equivalent vitrinite reflectance $\left(\% R_{\mathrm{o}}\right)$ values and the percent conversion of hydrocarbon (dotted line) are shown. Redrawn from Tang et al (2005).

Figure 17. Difference in $\delta \mathrm{D}$ values between LMW $n$-alkanes and $\mathrm{Pr}+\mathrm{Ph}$ versus the API gravity or pristane/heptadecane ratio (here a proxy for biodegradation) from a series of lightly biodegraded oils of the Upper Indus Basin. The isotopic contrast between these molecules increases with biodegradation primarily because $n$-alkanes are fractionated by this process whereas isoprenoid hydrocarbons are not. Redrawn from Asif et al (2009).

Figure 18. Saturate fraction $\delta \mathrm{D}$ values from the marine/evaporitic Alagamar Fm (left) and lacustrine Pendencia Fm (right) of the Potiguar Basin, Brazil. The large shift in $\delta \mathrm{D}$ is attributed to changing meteoric water composition. Redrawn from Santos Neto et al (1998).

Figure 19. $\delta \mathrm{D}$ values of hopanes (circles) and tri/tetracyclic terpanes (squares) from rock extracts and oils of the lacustrine Pendencia Fm, Potiguar Basin. The horizontal gray bar indicates the calculated value for equilibrium with coeval formation waters (triangles). Redrawn from Ferreira et al. (2012). 
Figure 20. $\delta \mathrm{D}$ values of $n$-alkanes from produced oils in the Western Canadian Sedimentary Basin. Redrawn from Li et al (2001).

Figure 21. $\delta \mathrm{D}$ values of $n$-alkanes from two series of oils from related sources but differing in maturity. There is a clear increase in $\delta \mathrm{D}$ with maturity. Note also the slope of $\delta \mathrm{D}$ versus carbon number. Redrawn from Li et al (2001).

Figure 22. $\delta \mathrm{D}$ values of $n$-alkanes from oils produced from the Otway Basin of southeastern Australia. $\mathrm{OA}, \mathrm{OB}$, and $\mathrm{OC}$ are related oil families. The large range in $\delta \mathrm{D}$ is interpreted as reflecting a primary meteoric water signal. Redrawn from Schimmelmann et al (2004).

Figure 23. $\delta \mathrm{D}$ values of $n$-alkanes in oils derived from the terrestrial Eocene Shahejie Formation, Liaohe basin, NE China. Dashed lines represent the freshwater paralic source (E3), while solid lines represent the saline/hypersaline lacustrine source (E4). Redrawn from Xiong et al (2005).

Figure 24. $\delta \mathrm{D}$ values of diterpane biomarkers extracted from the Eocene Shahejie Formation, Liaohe basin, NE China. The large differences between molecules are interpreted as representing primary biosynthetic differences. Redrawn from Tuo et al (2006).

Figure 25. $\delta \mathrm{D}$ values of $n$-alkanes from oils sourced in the upper (left panel) and lower (right panel) Paleozoic rocks of the Huanghua subbasin, NE China. Redrawn from Liu et al (2006).

Figure 26. $\delta \mathrm{D}$ values of $n$-alkanes from Lower Paleozoic carbonate rocks of the Jiyang subbasin, NE China. Left panel are those obtained by solvent extraction of the crushed rock, right panel are those obtained after acid dissolution of carbonates. Redrawn from Xiong et al (2007). 


\section{References Cited}

Aggarwal P. K., Araguás-Araguás L. J., Groening M., Kulkarni K. M., Kurttas T., Newman B. D. and Vitvar T. (2010) Global hydrological isotope data and data networks. In Isoscapes: Understanding Movement, Pattern, and Process on Earth Through Isotope Mapping (eds. J. B. West, G. J. Bowen, T. E. Dawson, and K. P. Tu). Springer, pp. 33-50.

Alexander R., Kagi R. and Larcher A. (1984) Clay catalysis of alkyl hydrogen exchange reactionsreaction mechanisms. Organic Geochemistry 6, 755-760.

Alexander R., Kagi R. and Larcher A. (1982) Clay catalysis of aromatic hydrogen-exchange reactions. Geochimica et Cosmochimica Acta 46, 219-222.

Alexander R., Kagi R., Larcher A. and Woodhouse G. (1981) Aromatic hydrogen exchange in petroleum source rocks, In Advances in Organic Geochemistry 1981 (Edited by M. Bjoroy et al.), 69-71

Andersen N., Paul H., Bernasconi S., McKenzie J., Behrens A., Schaeffer P. and Albrecht P. (2001) Large and rapid climate variability during the Messinian salinity crisis: Evidence from deuterium concentrations of individual biomarkers. Geology 29, 799-802.

Asif M., Grice K. and Fazeelat T. (2009) Assessment of petroleum biodegradation using stable hydrogen isotopes of individual saturated hydrocarbon and polycyclic aromatic hydrocarbon distributions in oils from the Upper Indus Basin, Pakistan. Organic Geochemistry 40, 301-311.

Burgoyne T. and Hayes J. M. (1998) Quantitative production of H2 by pyrolysis of gas chromatographic effluents. Analytical Chemistry 70, 5136-5141.

Campbell B. J., Li C., Sessions A. L. and Valentine D. L. (2009) Hydrogen isotopic fractionation in lipid biosynthesis by H2-consuming Desulfobacterium autotrophicum. Geochimica et Cosmochimica Acta 73, 2744-2757.

Chikaraishi Y., Tanaka R., Tanaka A. and Ohkouchi N. (2009) Fractionation of hydrogen isotopes during phytol biosynthesis. Organic Geochemistry 40, 569-573.

Clark I. D. and Fritz P. (1997) Environmental Isotopes in Hydrogeology CRC Press, Boca Raton, FL. pp. $1-312$.

Clayton C. J. (1991) Effect of maturity on carbon isotope ratios of oils and condensates. Organic Geochemistry 17, 887-899. 
Clayton C. J. and Bjoroy M. (1994) Effect of maturity on ${ }^{13} \mathrm{C} /{ }^{12} \mathrm{C}$ ratios of individual compounds in North Sea oils. Organic Geochemistry 21, 737-750.

Craig H. and Gordon L. I. (1965) Deuterium and oxygen 18 variations in the ocean and the marine atmosphere. In Stable Isotopes in Oceanographic Studies and Paleotemperatures. (ed. E. Tongiorgi)Consiglio nazionale delle richerche, Laboratorio de geologia nucleare, Spoleto, Italy. pp. 9131.

Dawson D., Grice K., Wang S., Alexander R. and Radke J. (2004) Stable hydrogen isotopic composition of hydrocarbons in torbanites (Late Carboniferous to Late Permian) deposited under various climatic conditions. Organic Geochemistry 35, 189-197.

Dawson D., Grice K. and Alexander R. (2005) Effect of maturation on the indigenous delta D signatures of individual hydrocarbons in sediments and crude oils from the Perth Basin (Western Australia). Organic Geochemistry 36, 95-104.

Dawson D., Grice K., Alexander R. and Edwards D. (2007) The effect of source and maturity on the stable isotopic compositions of individual hydrocarbons in sediments and crude oils from the Vulcan Subbasin, Timor Sea, Northern Australia. Organic Geochemistry 38, 1015-1038.

Estep M. and Hoering T. (1980) Biogeochemistry of the stable hydrogen isotopes. Geochimica et Cosmochimica Acta 44, 1197-1206.

Feakins S. J. (2013) Pollen-corrected leaf wax D/H reconstructions of northeast African hydrological changes during the late Miocene. Paleogeography, Paleoclimatology, Paleoecology, 1-10.

Feakins S. J. and Sessions A. L. (2010) Controls on the D/H ratios of plant leaf waxes in an arid ecosystem. Geochimica et Cosmochimica Acta 74, 2128-2141.

Feng X. and Epstein S. (1995) Climatic temperature records in dD from tree rings. Geochimica et Cosmochimica Acta 59, 3029-3037.

Ferreira A. A., Neto E. V. S., Sessions A. L., Schimmelmann A. and Neto F. R. A. (2012) 2H/1H ratio of hopanes, tricyclic and tetracyclic terpanes in oils and source rocks from the Potiguar Basin, Brazil. Organic Geochemistry 51, 13-16.

Flanagan L., Comstock J. and Ehleringer J. R. (1991) Comparison of Modeled and Observed Environmental-Influences on the Stable Oxygen and Hydrogen Isotope Composition of Leaf Water in Phaseolus-Vulgaris L. Plant Physiology 96, 588-596. 
Friedman I. and Hardcastle K. (1988) Deuterium in interstitial water from deep-sea cores. Journal of Geophysical Research 93, 8249-8263.

Gao L., Zheng M., Fraser M. and Huang Y. (2014) Comparable hydrogen isotopic fractionation of plant leaf wax n-alkanoic acids in arid and humid subtropical ecosystems. Geochemistry, Geophysics, Geosystems 15, 361-373.

Gao L., Edwards E. J., Zeng Y. and Huang Y. (2014b) Major Evolutionary Trends in Hydrogen Isotope Fractionation of Vascular Plant Leaf Waxes ed. R. Aroca. PLoS ONE 9, e112610.

Gat J. R. (1984) The Stable Isotope Composition of Dead-Sea Waters. Earth and Planetary Science Letters 71, 361-376.

Gibson J. J. and Edwards T. W. D. (2002) Regional water balance trends and evaporation-transpiration partitioning from a stable isotope survey of lakes in northern Canada. Global Biogeochemical Cycles 16, doi:10.1029/2001GB001839.

Gonfiantini R. (1986) Environmental isotopes in lake studies. Handbook of environmental isotope geochemistry 2, 113-168.

Gray J. R., Lacrampe-Couloume G., Gandhi D., Scow K. M., Wilson R. D., Mackay D. M. and Sherwood Lollar B. (2002) Carbon and Hydrogen Isotopic Fractionation during Biodegradation of Methyl tert-Butyl Ether. Environmental Science \& Technology 36, 1931-1938.

Grice K., Lu H., Atahan P., Asif M., Hallmann C., Greenwood P., Maslen E., Tulipani S., Williford K. and Dodson J. (2009) New insights into the origin of perylene in geological samples. Geochimica et Cosmochimica Acta 73, 6531-6543.

Heider J. (2007) Adding handles to unhandy substrates: anaerobic hydrocarbon activation mechanisms. Current Opinion in Chemical Biology 11, 188-194.

Heinzelmann S. M., Villanueva L., Sinke-Schoen D., Sinninghe Damstã J. S., Schouten S. and van der Meer M. T. J. (2015) Impact of metabolism and growth phase on the hydrogen isotopic composition of microbial fatty acids. Frontiers in Microbiology 6, 408.

Hilkert A., Douthitt C., Schluter H. and Brand W. A. (1999) Isotope ratio monitoring GCMS of D/H by high temperature conversion isotope ratio mass spectrometry. Rapid Communications in Mass Spectrometry 13, 1226-1230.

Hopfner A. (1969) Vapor Pressure Isotope Effects. Angewandte Chemie 8, 689-699. 
Hou J., D'Andrea W., MacDonald D. and Huang Y. (2007) Hydrogen isotopic variability in leaf waxes among terrestrial and aquatic plants around Blood Pond, Massachusetts (USA). Organic Geochemistry 38, 977-984.

Hou J., Dandrea W. and Huang Y. (2008) Can sedimentary leaf waxes record D/H ratios of continental precipitation? Field, model, and experimental assessments. Geochimica et Cosmochimica Acta 72, 35033517.

Hunkeler D., Andersen N., Aravena R., Bernasconi S. and Butler B. (2001) Hydrogen and carbon isotope fractionation during aerobic biodegradation of benzene. Environmental Science \& Technology 35, 34623467.

Jones A. A., Sessions A. L., Campbell B., Li C. and Valentine D. L. (2008) D/H ratios of fatty acids from marine particulate organic matter in the California Borderland Basins. Organic Geochemistry 39, 485500.

Kahmen A., Simonin K., Tu K. P., Merchant A., Callister A., Siegwolf R., Dawson T. E. and Arndt S. K. (2008) Effects of environmental parameters, leaf physiological properties and leaf water relations on leaf water $\delta^{18} \mathrm{O}$ enrichment in different Eucalyptus species. Plant, Cell and Environment 31, 738-751.

Koepp M. (1978) D/H Isotope exchange reaction between petroleum and water: A contributory determinant for $\mathrm{D} / \mathrm{H}$-isotope ratios in crude oils? Short papers of the Fourth International Conference, Geochronology, Cosmochronology, Isotope geology, 1-3.

Kuder T., Wilson J., Kaiser P., Kolhatkar R., Philp P. and Allen J. (2005) Enrichment of stable carbon and hydrogen isotopes during anaerobic biodegradation of MTBE: Microcosm and field evidence.

Environmental Science \& Technology 39, 213-220.

Larter S. R., Bowler B., Li M., Chen M., Brincat D., Bennett B., Noke K., Donohoe P., Simmons D. and Kohnen M. (1996) Molecular indicators of secondary oil migration distances. Nature 383, 593-597.

Lecuyer C., Gillet P. and Robert F. (1998) The hydrogen isotope composition of seawater and the global water cycle. Chemical Geology 145, 249-261.

Leif R. and Simoneit B. R. T. (2000) The role of alkenes produced during hydrous pyrolysis of a shale. Organic Geochemistry 31, 1189-1208.

Li C., Sessions A. L., Kinnaman F. S. and Valentine D. L. (2009) Hydrogen-isotopic variability in lipids from Santa Barbara Basin sediments. Geochimica et Cosmochimica Acta 73, 4803-4823. 
Li C., Sessions A. L., Valentine D. L. and Thiagarajan N. (2011) D/H variation in terrestrial lipids from Santa Barbara Basin over the past 1400years: A preliminary assessment of paleoclimatic relevance. Organic Geochemistry 42, 15-24.

Li M., Huang Y., Obermajer M., Jiang C., Snowdon L. and Fowler M. (2001) Hydrogen isotopic compositions of individual alkanes as a new approach to petroleum correlation: case studies from the Western Canada Sedimentary Basin. Organic Geochemistry 32, 1387-1399.

Liu J., Geng A. and Xiong Y. (2006) The application of stable carbon and hydrogen isotopic compositions of individual n-alkanes to Paleozoic oil/source rock correlation enigmas in the Huanghua depression, China. Journal of Petroleum Science and Engineering 54, 70-78.

Majoube M. (1971) Fractionnement en oxygen et en deuterium entre l'eau et sa vapeur. Journal de Chimie Physique 68, 1423-1436.

Mancini S., Ulrich A., Lacrampe-Couloume G., Sleep B., Edwards E. and Lollar B. (2003) Carbon and hydrogen isotopic fractionation during anaerobic biodegradation of benzene. Applied and Environmental Microbiology 69, 191-198.

Maslen E., Grice K., Dawson D., Wang S., and Horsfield B. (2012) Stable hydrogen isotopes of isoprenoids and $n$-alkanes as a proxy for estimating the thermal history of sediments through geological time. in Analyzing the Thermal History of Sedimentary Basins: Methods and Case Studies, N.B. Harris and K.E. Peters eds, Society for Sedimentary Geology special publication 103, 29-43.

McInerney F. A., Helliker B. R. and Freeman K. H. (2011) Hydrogen isotope ratios of leaf wax n-alkanes in grasses are insensitive to transpiration. Geochimica et Cosmochimica Acta 75, 541-554.

Meinzer F. C., Andrade J. L., Goldstein G., Holbrook N. M., Cavelier J. and Wright S. J. (1999) Partitioning of soil water among canopy trees in a seasonally dry tropical forest. Oecologia 121, 293-301. Merlivat L. and Nief G. (1967) Fractionnement isotopique lors des changements d'état solide-vapeur et liquide-vapeur de l'eau à des temperatures inferieures à $0{ }^{\circ} \mathrm{C}$. Tellus $19,122-126$.

Nabbefeld B., Grice K., Schimmelmann A., Sauer P. E., Böttcher M. E. and Twitchett R. (2010a) Significance of $\delta \mathrm{D}_{\text {kerogen, }} \delta^{13} \mathrm{C}_{\text {kerogen }}$ and $\delta^{34} \mathrm{~S}_{\text {pyrite }}$ from several Permian/Triassic (P/Tr) sections. Earth and Planetary Science Letters 295, 21-29.

Nabbefeld B., Grice K., Twitchett R. J., Summons R. E., Hays L., Böttcher M. E. and Asif M. (2010b) An integrated biomarker, isotopic and palaeoenvironmental study through the Late Permian event at Lusitaniadalen, Spitsbergen. Earth and Planetary Science Letters 291, 84-96. 
Naraoka H., Uehara T., Hanada S. and Kakegawa T. (2010) $\delta 13 \mathrm{C}-\delta \mathrm{D}$ distribution of lipid biomarkers in a bacterial mat from a hot spring in Miyagi Prefecture, NE Japan. Organic Geochemistry 41, 398-403. Newberry S. L., Kahmen A., Dennis P. and Grant A. (2015) n-Alkane biosynthetic hydrogen isotope fractionation isnot constant throughout the growing season in the riparian treeSalix viminalis. Geochimica et Cosmochimica Acta 165, 75-85.

Osburn M. R., Sessions A. L., Pepe-Ranney C. and Spear J. R. (2011) Hydrogen-isotopic variability in fatty acids from Yellowstone National Park hot spring microbial communities. Geochimica et Cosmochimica Acta 75, 4830-4845.

Osburn M.R. (2013) Isotopic proxies for microbial and environmental change. PhD Thesis, California Institute of technology.

Payne B. R. (1970) Water balance of Lake Chala and its relation to groundwater from tritium and stable isotope data. Journal of Hydrology 11, 47-58.

Pedentchouk N., Freeman K. and Harris N. (2006) Different response of delta D values of n-alkanes, isoprenoids, and kerogen during thermal maturation. Geochimica et Cosmochimica Acta 70, 2063-2072.

Piasecki A., Sessions A.L., Eiler J.M. (in review) Prediction of equilibrium isotope effects in methane, ethane and propane using density functional theory. Geochimica et Cosmochimica Acta.

Pond K., Huang Y., Wang Y. and Kulpa C. (2002) Hydrogen isotopic composition of individual nalkanes as an intrinsic tracer for bioremediation and source identification of petroleum contamination. Environmental Science \& Technology 36, 724-728.

Radke J., Bechtel A., Gaupp R., Puttmann W., Schwark L., Sachse D. and Gleixner G. (2005) Correlation between hydrogen isotope ratios of lipid biomarkers and sediment maturity. Geochimica et Cosmochimica Acta 69, 5517-5530.

Rigby D., Batts B. D. and Smith J. W. (1981) The effect of maturation on the isotopic composition of fossil fuels. Organic Geochemistry 3, 29-36.

Robins R., Billault I., Duan J., Guiet S., Pionnier S. and Zhang B.-L. (2003) Measurement of 2H distribution in natural products by quantitative 2H NMR: An approach to understanding metabolism and enzyme mechanism? Phytochemistry Reviews 2, 87-102.

Romero I. C. and Feakins S. J. (2011) Spatial gradients in plant leaf wax D/H across a coastal salt marsh in southern California. Organic Geochemistry 42, 618-629. 
Rozanski K., Araguás L. A. and Gonfiantini R. (1993) Isotopic patterns in modern global precipitation. In Climate Change in Continental Isotopic Records American Geophysical Union, 1-36.

Sachs J. P. and Schwab V. F. (2011) Hydrogen isotopes in dinosterol from the Chesapeake Bay estuary. Geochimica et Cosmochimica Acta 75, 444-459.

Sachse D., Billault I., Bowen G. J., Chikaraishi Y., Dawson T. E., Feakins S. J., Freeman K. H., Magill C. R., McInerney F. A., van der Meer M. T. J., Polissar P., Robins R. J., Sachs J. P., Schmidt H.-L., Sessions A. L., White J. W. C., West J. B. and Kahmen A. (2012) Molecular Paleohydrology: Interpreting the Hydrogen-Isotopic Composition of Lipid Biomarkers from Photosynthesizing Organisms. Annual Reviews of Earth and Planetary Science 40, 221-249.

Sachse D. and Sachs J. P. (2008) Inverse relationship between D/H fractionation in cyanobacterial lipids and salinity in Christmas Island saline ponds. Geochimica et Cosmochimica Acta 72, 793-806.

Santos Neto dos E. and Hayes J. M. (1999) Use of hydrogen and carbon stable isotopes characterizing oils from the Potiguar Basin (onshore) Northeastern Brazil. AAPG Bulletin 83, 496-518.

Santos Neto dos E. V., Hayes J. M. and Takaki T. (1998) Paleoclimatic assessment of Cretaceous lacustrine and marine evaporitic sequences from the Potiguar Basin (Brazil) based on the hydrogen isotopic compositions of saturated hydrocarbons. Revista Latino Americana de Geoquimica Organica 4, $5-24$.

Santos-Neto E. (1996) Isotopic characterization of the Cretaceous lacustrine and of the marine-evaporitic sequences, and related oils from the potiguar basin, northeastern brazil. Ph.D. Thesis, Indiana University.

Sauer P. E., Eglinton T. I., Hayes J. M., Schimmelmann A. and Sessions A. L. (2001) Compound-specific $\mathrm{D} / \mathrm{H}$ ratios of lipid biomarkers from sediments as a proxy for environmental and climatic conditions. Geochimica et Cosmochimica Acta 65, 213-222.

Schiegl W. and Vogel J. (1970) Deuterium content of organic matter. Earth and Planetary Science Letters 7, 307-313.

Schimmelmann A., Sessions A. L. and Mastalerz M. (2006) Hydrogen isotopic (D/H) composition of organic matter during diagenesis and thermal maturation. Annual Reviews of Earth and Planetary Science 34, 501-533.

Schimmelmann A., Sessions A. L., Boreham C., Edwards D., Logan G. A. and Summons R. E. (2004) D/H ratios in terrestrially sourced petroleum systems. Organic Geochemistry 35, 1169-1195. 
Schmidt H., Werner R. and Eisenreich W. (2003) Systematics of ${ }^{2} \mathrm{H}$ patterns in natural compounds and its importance for the elucidation of biosynthetic pathways. Phytochemistry Reviews 2, 61-85.

Schoell M. (1984) Recent advances in petroleum isotope geochemistry. Organic Geochemistry 6, 645663.

Schoell M. (1980) The hydrogen and carbon isotopic composition of methane from natural gases of various origins. Geochimica et Cosmochimica Acta 44, 649-661.

Schouten S., Ossebaar J., Schreiber K., Kienhuis M., Langer G., Benthien A. and Bijma J. (2006) The effect of temperature, salinity and growth rate on the stable hydrogen isotopic composition of long chain alkenones produced by Emiliania huxleyi and Gephyrocapsa oceanica. Biogeosciences 3, 113-119.

Scrimgeour C., Begley I. and Thomason M. (1999) Measurement of deuterium incorporation into fatty acids by gas chromatography/isotope ratio mass spectrometry. Rapid Communications in Mass

Spectrometry 13, 271-274.

Sessions A. L., Burgoyne T., Schimmelmann A. and Hayes J. M. (1999) Fractionation of hydrogen isotopes in lipid biosynthesis. Organic Geochemistry 30, 1193-1200.

Sessions A. L., Sylva S. P., Summons R. E. and Hayes J. M. (2004) Isotopic exchange of carbon-bound hydrogen over geologic timescales. Geochimica et Cosmochimica Acta 68, 1545-1559.

Sessions A. L. (2006) Seasonal changes in D/H fractionation accompanying lipid biosynthesis in Spartina alternflora. Geochimica et Cosmochimica Acta 70, 2153-2162.

Sessions A. L. (2006) Isotope-ratio detection for gas chromatography. Journal of Separation Science 29, 1946-1961.

Sheppard S. M. and Epstein S. (1970) D/H and ${ }^{18} \mathrm{O} /{ }^{16} \mathrm{O}$ ratios of minerals of possible mantle or lower crustal origin. Earth and Planetary Science Letters 9, 232-239.

Smith B. and Epstein S. (1970) Biogeochemistry of the stable isotopes of hydrogen and carbon in salt marsh biota. Plant Physiology 46, 738-742.

Smittenberg R. H., Saenger C., Dawson M. N. and Sachs J. P. (2011) Compound-specific D/H ratios of the marine lakes of Palau as proxies for West Pacific Warm Pool hydrologic variability. Quaternary Science Reviews 30, 921-933.

Sternberg L. S. L., Deniro M. and Ajie H. (1984) Stable hydrogen isotope ratios of saponifiable lipids and cellulose nitrate from CAM, C3 and C4 plants. Phytochemistry 23, 2475-2477. 
Summons R. E., Freeman K. H., Grice K. and Pancost R. D. (2008) Where would we be without the isotopes? Organic Geochemistry 39, 483-484.

Sun Y., Chen Z., Xu S. and Cai P. (2005) Stable carbon and hydrogen isotopic fractionation of individual -alkanes accompanying biodegradation: evidence from a group of progressively biodegraded oils.

Organic Geochemistry 36, 225-238.

Tang Y., Huang Y., Ellis G., Wang Y., Kralert P., Gillaizeau B., Ma Q. and Hwang R. (2005) A kinetic model for thermally induced hydrogen and carbon isotope fractionation of individual n-alkanes in crude oil. Geochimica et Cosmochimica Acta 69, 4505-4520.

Tang Y., Perry J., Jenden P. and Schoell M. (2000) Mathematical modeling of stable carbon isotope ratios in natural gases. Geochimica et Cosmochimica Acta 64, 2673-2687.

Tipple B. J., Berke M. A., Doman C. E., Khachaturyan S. and Ehleringer J. R. (2013) Leaf-wax n-alkanes record the plant-water environment at leaf flush. Proceedings of the National Academy of Sciences of the United States 110, 2659-2664.

Tuo J., Zhang M., Wang X. and Zhang C. (2006) Hydrogen isotope ratios of aliphatic and diterpenoid hydrocarbons in coals and carbonaceous mudstones from the Liaohe Basin, China. Organic Geochemistry 37, 165-176.

Urey H. C. and Teal G. K. (1935) The hydrogen isotope of atomic weight two. Reviews of Modern Physics 7, 34 .

Valentine D. L., Sessions A. L., Tyler S. and Chidthaisong A. (2004) Hydrogen isotope fractionation during $\mathrm{H} 2 / \mathrm{CO} 2$ acetogenesis: hydrogen utilization efficiency and the origin of lipid-bound hydrogen. Geobiology 2, 179-188.

Valentine D. L. (2009) Isotopic remembrance of metabolism past. Proceedings of the National Academy of Sciences of the United States 106, 12565-12566.

Wang Yi and Huang Y. (2003) Hydrogen isotopic fractionation of petroleum hydrocarbons during vaporization: implications for assessing artificial and natural remediation of petroleum contamination. Applied Geochemistry 18, 1641-1651.

Wang Ying, Sessions A. L., Nielsen R. J. and Goddard W. A. (2009a) Equilibrium 2H/1H fractionations in organic molecules. II: Linear alkanes, alkenes, ketones, carboxylic acids, esters, alcohols and ethers. Geochimica et Cosmochimica Acta 73, 7076-7086. 
Wang Ying, Sessions A. L., Nielsen R. J. and Goddard W. A. III (2013) Equilibrium 2H/1H fractionation in organic molecules: III. Cyclic ketones and hydrocarbons. Geochimica et Cosmochimica Acta 107, 8295.

Wang Ying, Sessions A. L., Nielsen R. J. and Goddard W. A. III (2009b) Equilibrium 2H/1H fractionations in organic molecules: I. Experimental calibration of ab initio calculations. Geochimica et Cosmochimica Acta 73, 7060-7075.

Ward J., Ahad J., Lacrampe-Couloume G., Slater G. F., Edwards E. and Lollar B. (2000) Hydrogen isotope fractionation during methanogenic degradation of toluene: Potential for direct verification of bioremediation. Environmental Science \& Technology 34, 4577-4581.

West J. B., Ehleringer J. R. and Cerling T. E. (2007) Geography and Vintage Predicted by a Novel GIS Model of Wine $\delta$ 180. Journal of Agriculture and Food Chemistry 55, 7075-7083.

Whiticar M., Faber E. and Schoell M. (1986) Biogenic methane formation in marine and freshwater environments: CO2 reduction vs. acetate fermentation-Isotope evidence. Geochimica et Cosmochimica Acta 50, 693-709.

Williford K. H., Grice K., Logan G. A., Chen J. and Huston D. (2011) The molecular and isotopic effects of hydrothermal alteration of organic matter in the Paleoproterozoic McArthur River $\mathrm{Pb} / \mathrm{Zn} / \mathrm{Ag}$ ore deposit. Earth and Planetary Science Letters 301, 382-392.

Xiong Y., Geng A., Pan C., Liu D. and Peng P. (2005) Characterization of the hydrogen isotopic composition of individual $n$-alkanes in terrestrial source rocks. Applied Geochemistry 20, 455-464.

Xiong Y., Wang Y., Wang Y. and Xu S. (2007) Compound-specific C- and H-isotope compositions of enclosed organic matter in carbonate rocks: Implications for source identification of sedimentary organic matter and paleoenvironmental reconstruction. Applied Geochemistry 22, 2553-2565.

Yang H., Pagani M., Briggs D. E. G., Equiza M. A., Jagels R., Leng Q. and Lepage B. A. (2009) Carbon and hydrogen isotope fractionation under continuous light: implications for paleoenvironmental interpretations of the High Arctic during Paleogene warming. Oecologia 160, 461-470.

Yeh H.-W. and Epstein S. (1981) Hydrogen and carbon isotopes of petroleum and related organic matter. Geochimica et Cosmochimica Acta 45, 753-762.

Zborowski G., Ponticorvo L. and Rittenberg D. (1967) On the constancy of the deuterium fractionation in the biosynthesis of fatty acids since the Miocene Period. Biochemistry 58, 1660-1663. 
Zhang Z. and Sachs J. P. (2007) Hydrogen isotope fractionation in freshwater algae: I. Variations among lipids and species. Organic Geochemistry 38, 582-608.

Zhang X., Gillespie A. L. and Sessions A. L. (2009) Large D/H variations in bacterial lipids reflect central metabolic pathways. Proceedings of the National Academy of Sciences of the United States 106, $12580-12586$.

Zhang Z., Sachs J. P. and Marchetti A. (2009) Hydrogen isotope fractionation in freshwater and marine algae: II. Temperature and nitrogen limited growth rate effects. Organic Geochemistry 40, 428-439. 

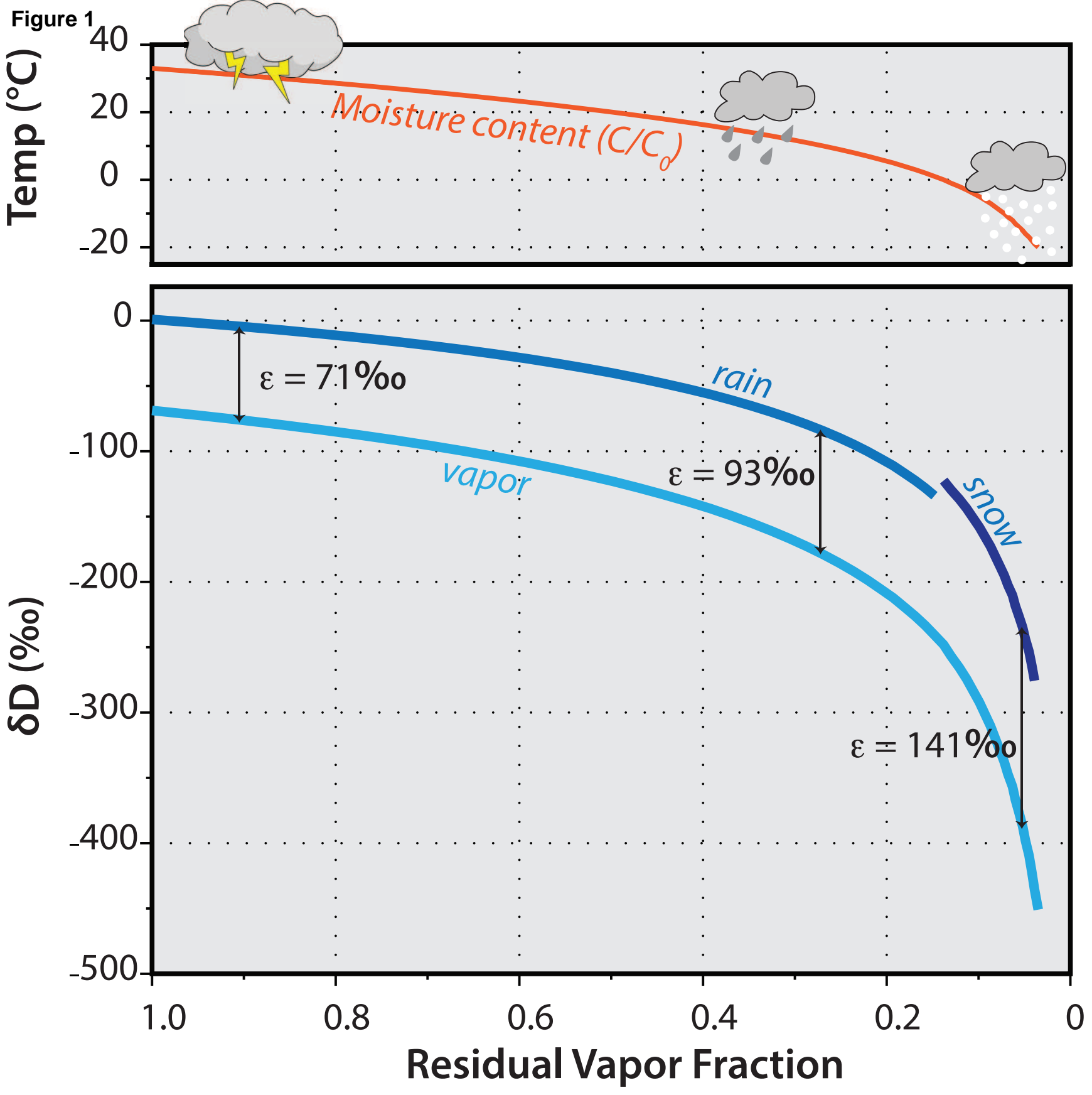

Figure 1

1-column

color (CMYK) 


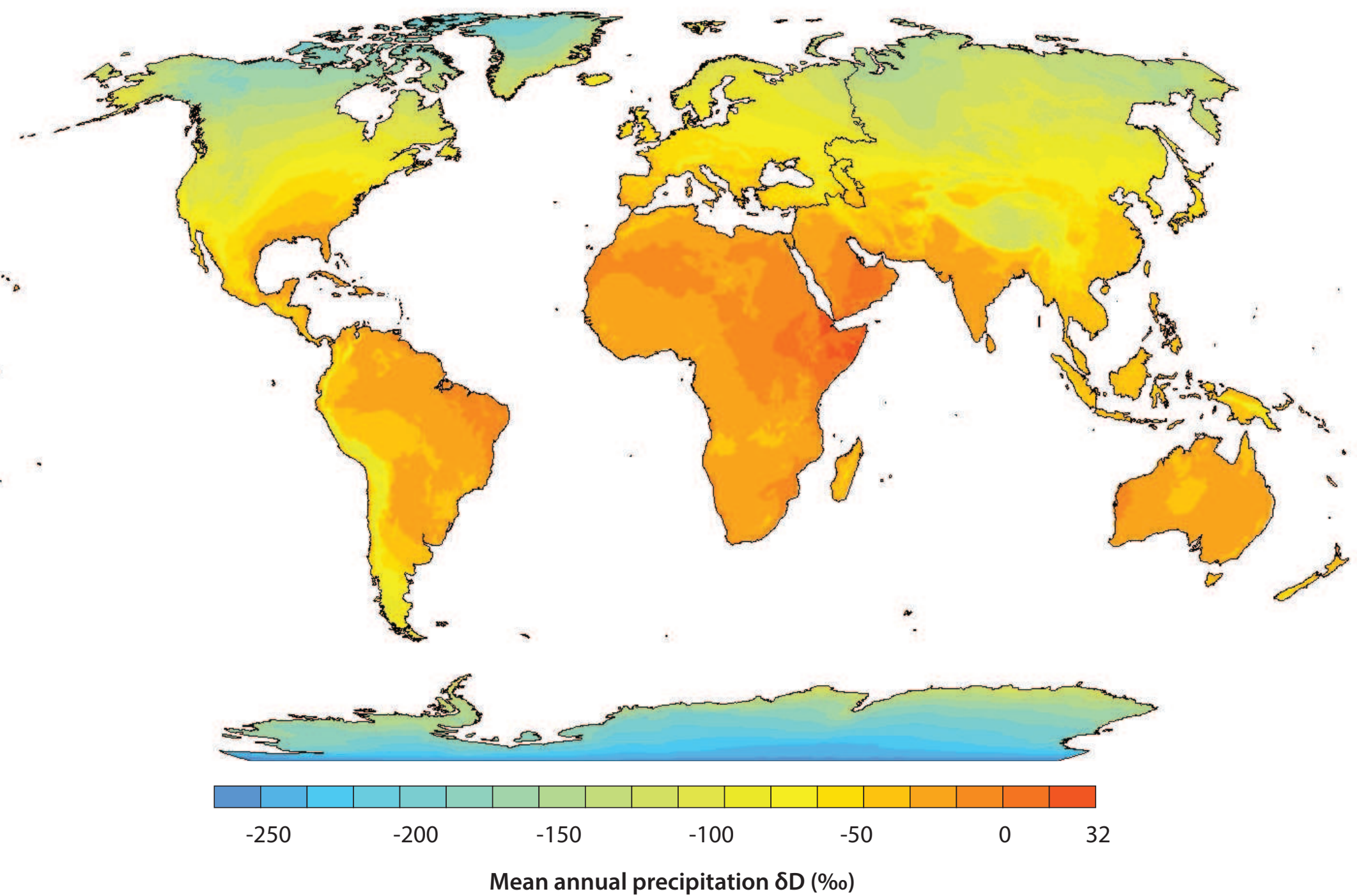




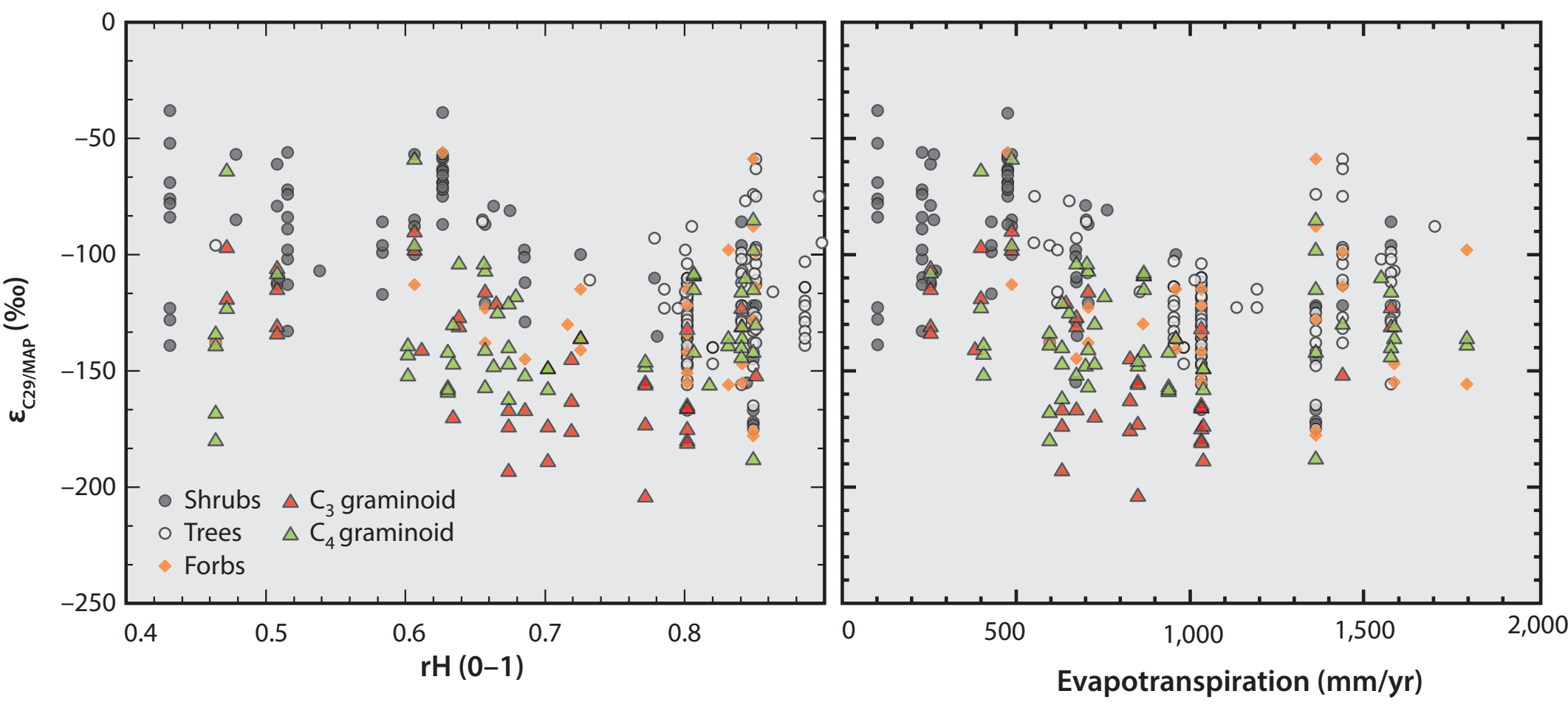

Figure 3 
Figure 4

isoprenoid

skeletons

$\mathrm{n}=245$

$n$-alkyl skeletons

$-500$

$-400$

$-300$

$-200$

$-100$

$\mathrm{n}=602$

$\delta \mathrm{D}(\% \mathrm{o})$

Figure 4

\section{1-column \\ color (CMYK)}


Figure 50

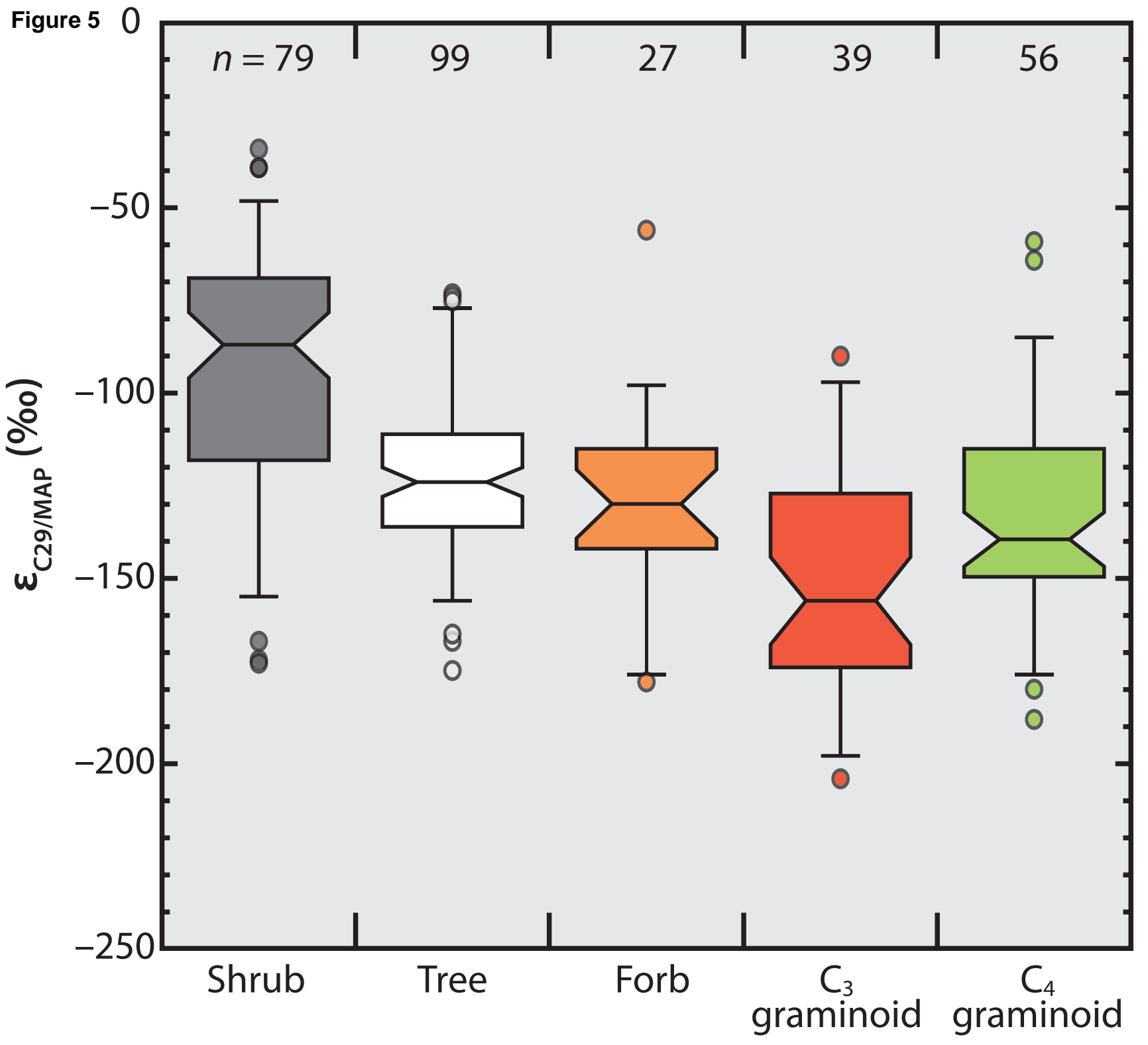

Growth form

Figure 5

1-column

color (CMYK) 
Figure 6

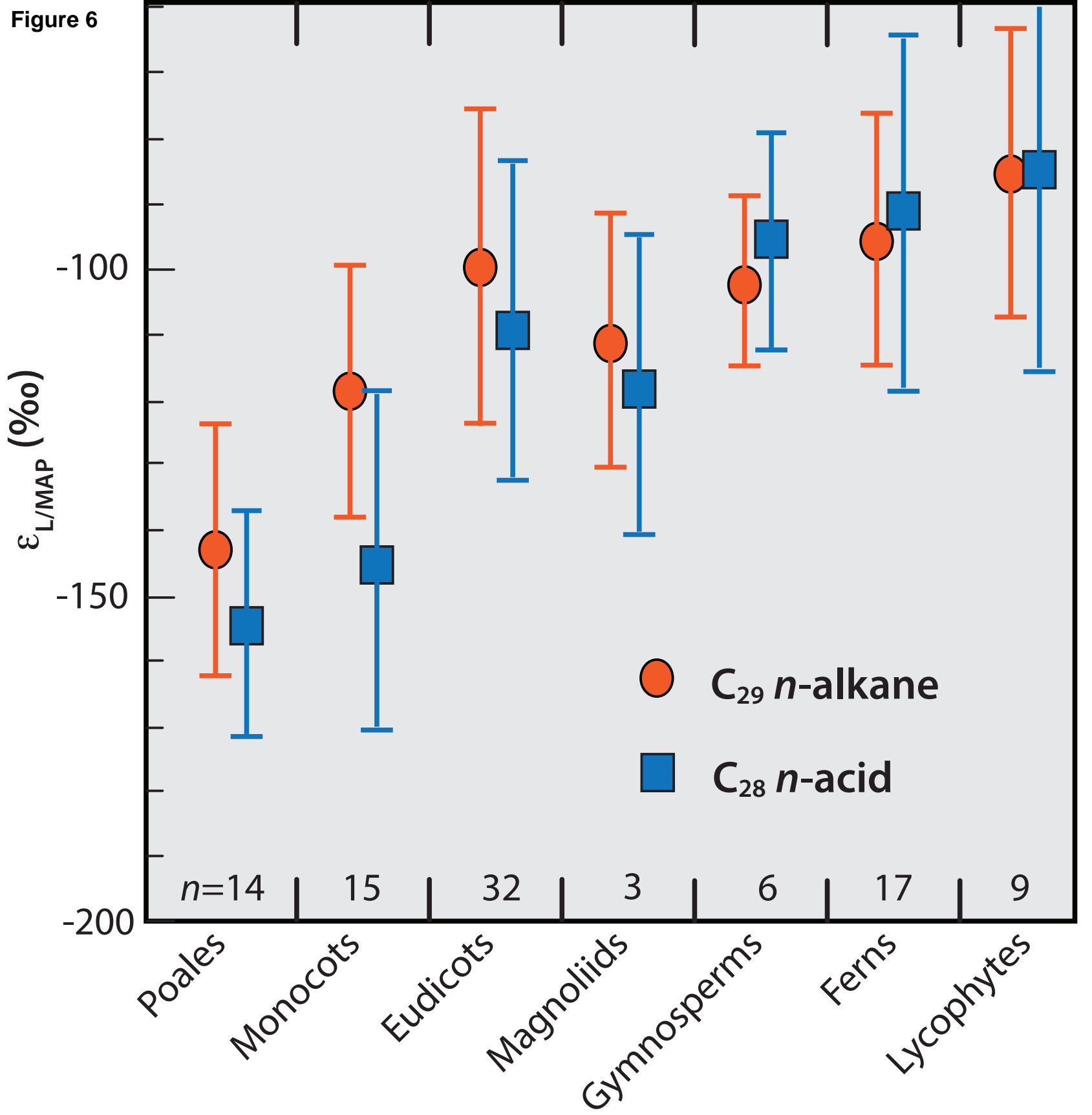

Figure 6

1-column color (CMYK) 
Figure 7

Autotrophs

Heterotrophs

\section{Chemohydrotrophs Photohydrotrophs}

C1 or other

Ferredoxin

TCA cycle

Pentose Phosphate, (acetate, succinate)

\section{Entner Doudoroff}

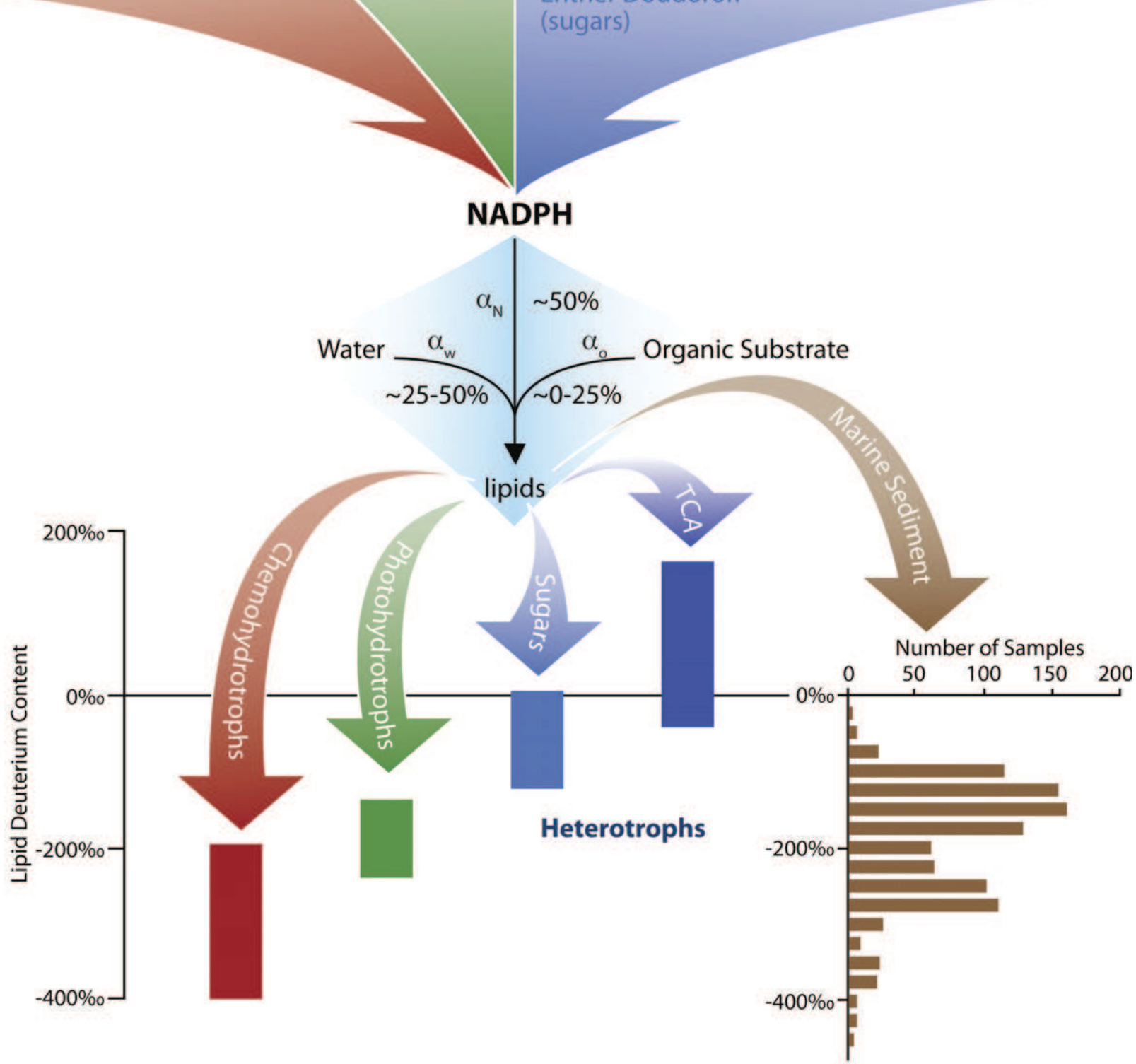

Culture Studies

Natural Samples

Figure 7

1-column

color (CMYK) 


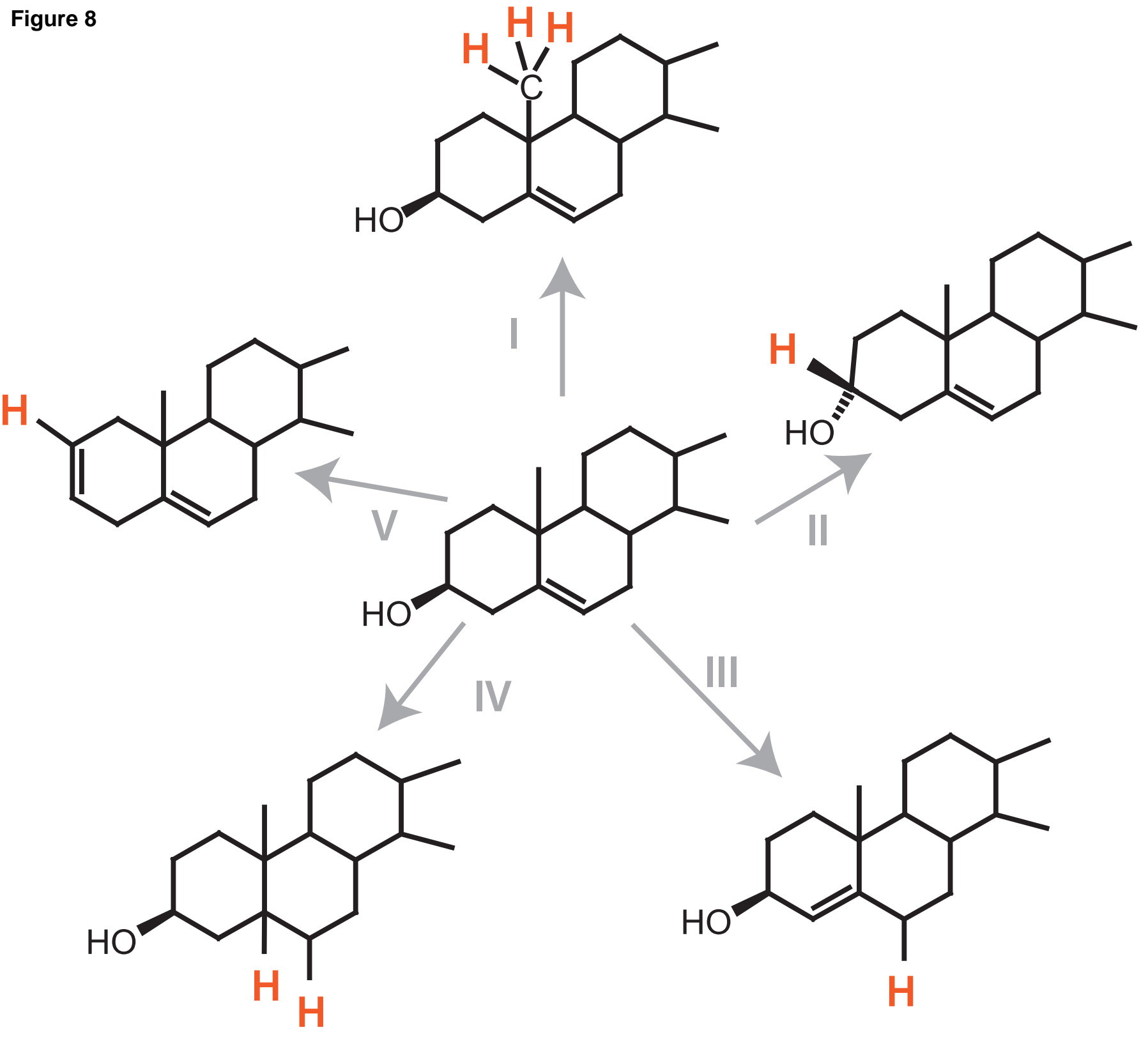

Figure 8 1-column 


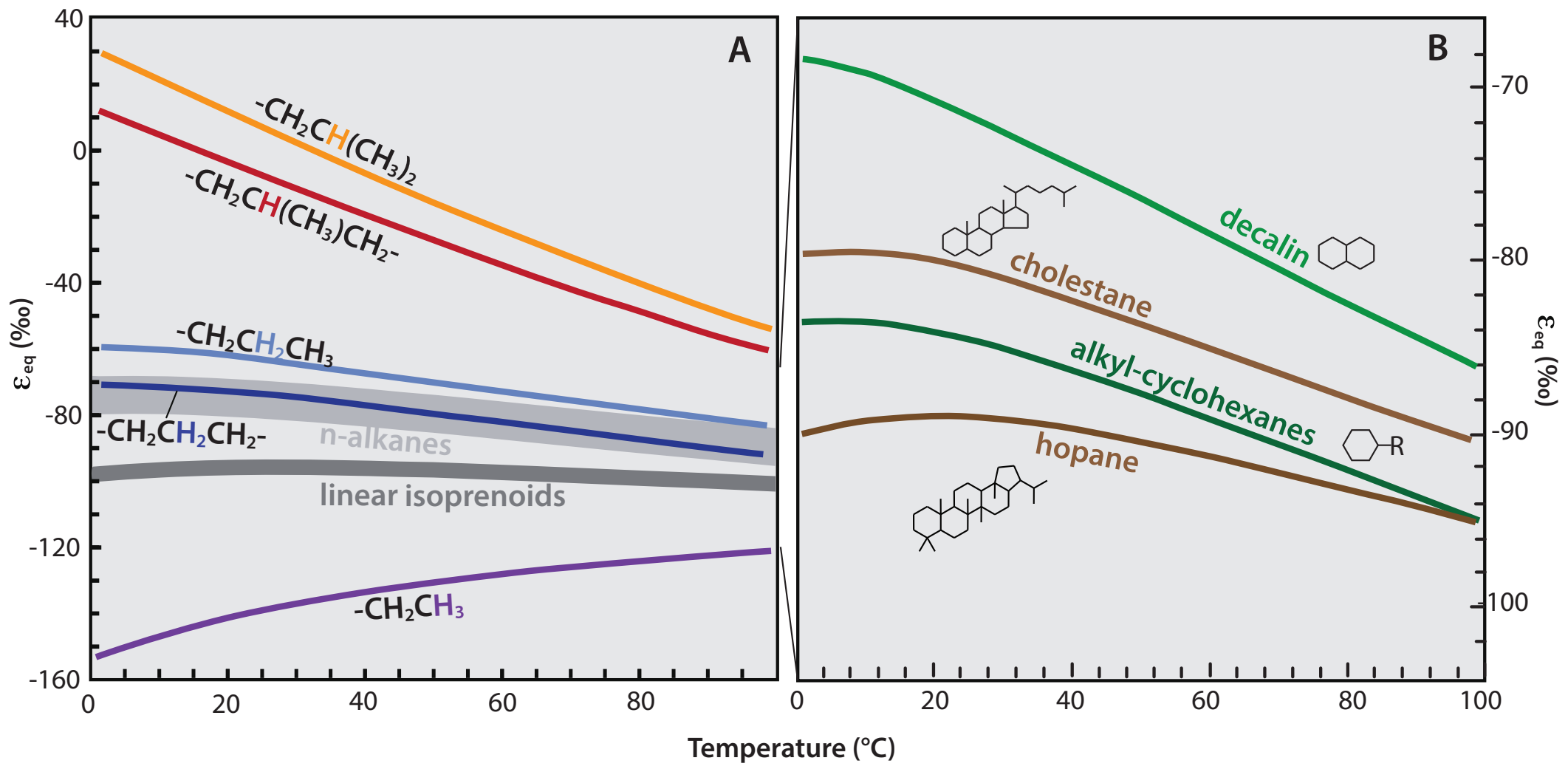

Figure 13

2-column color (CMYK) 


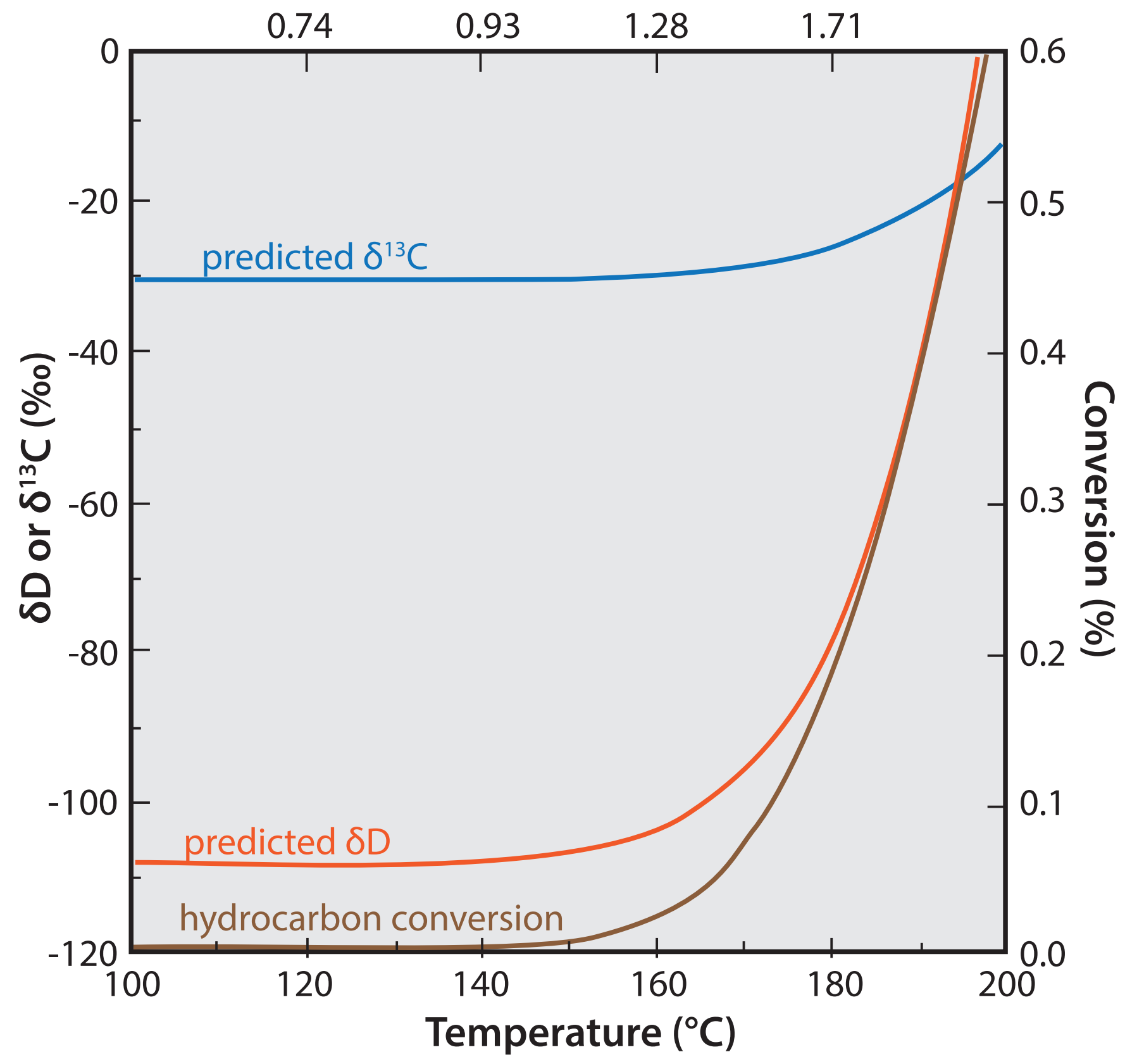

Figure 16 1-column color (CMYK) 


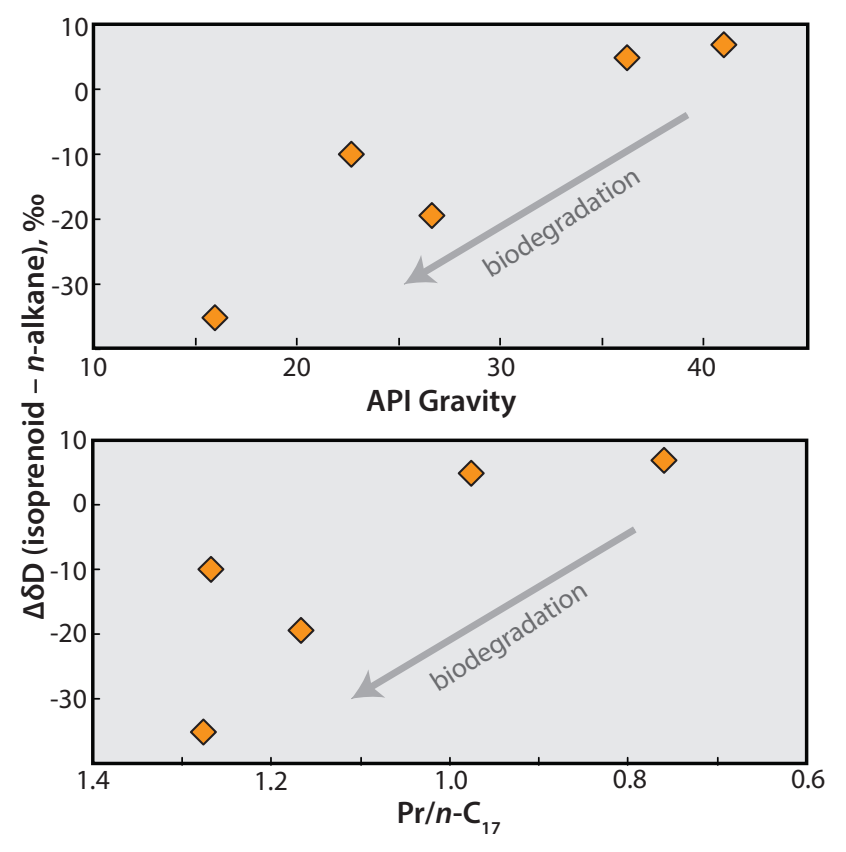

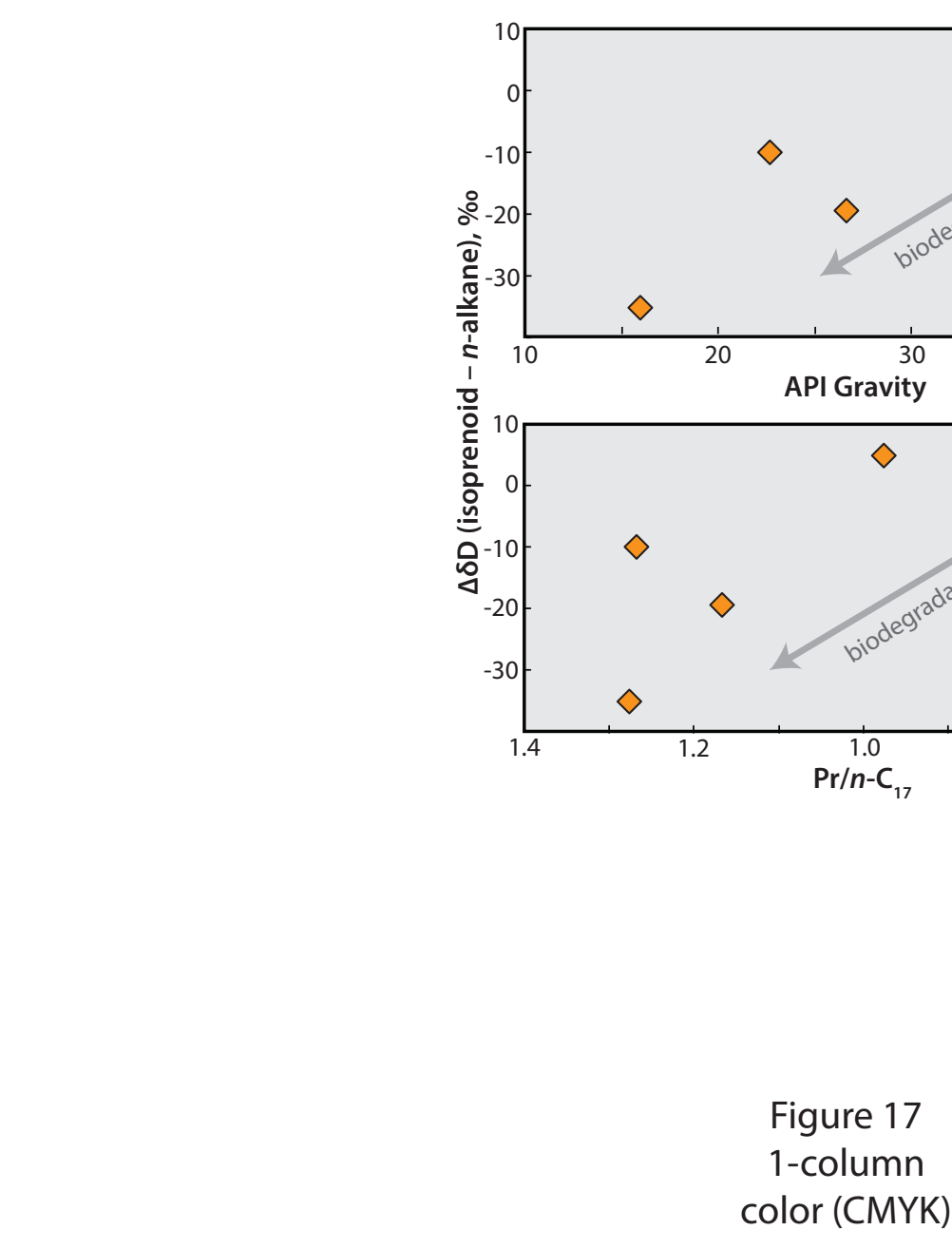

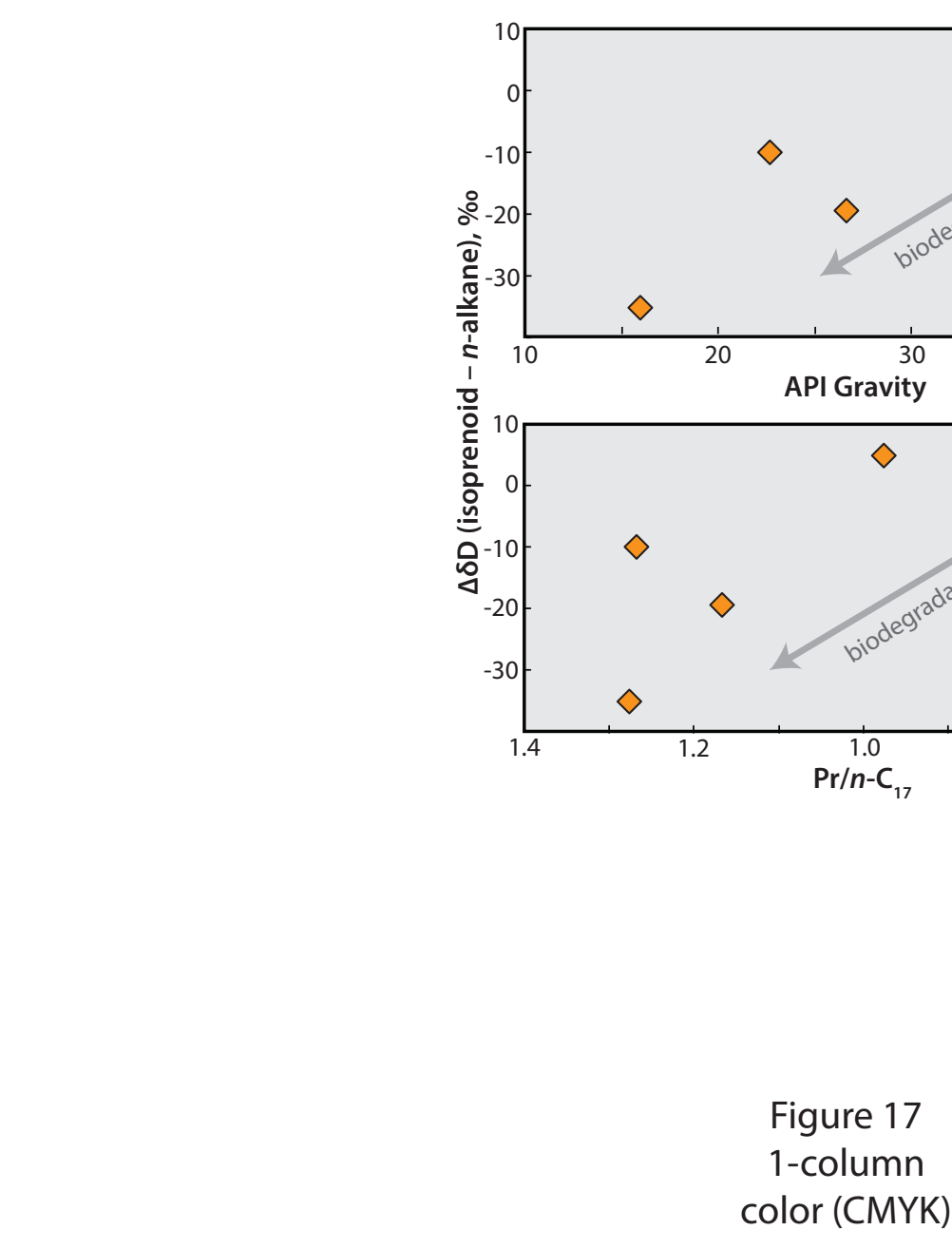

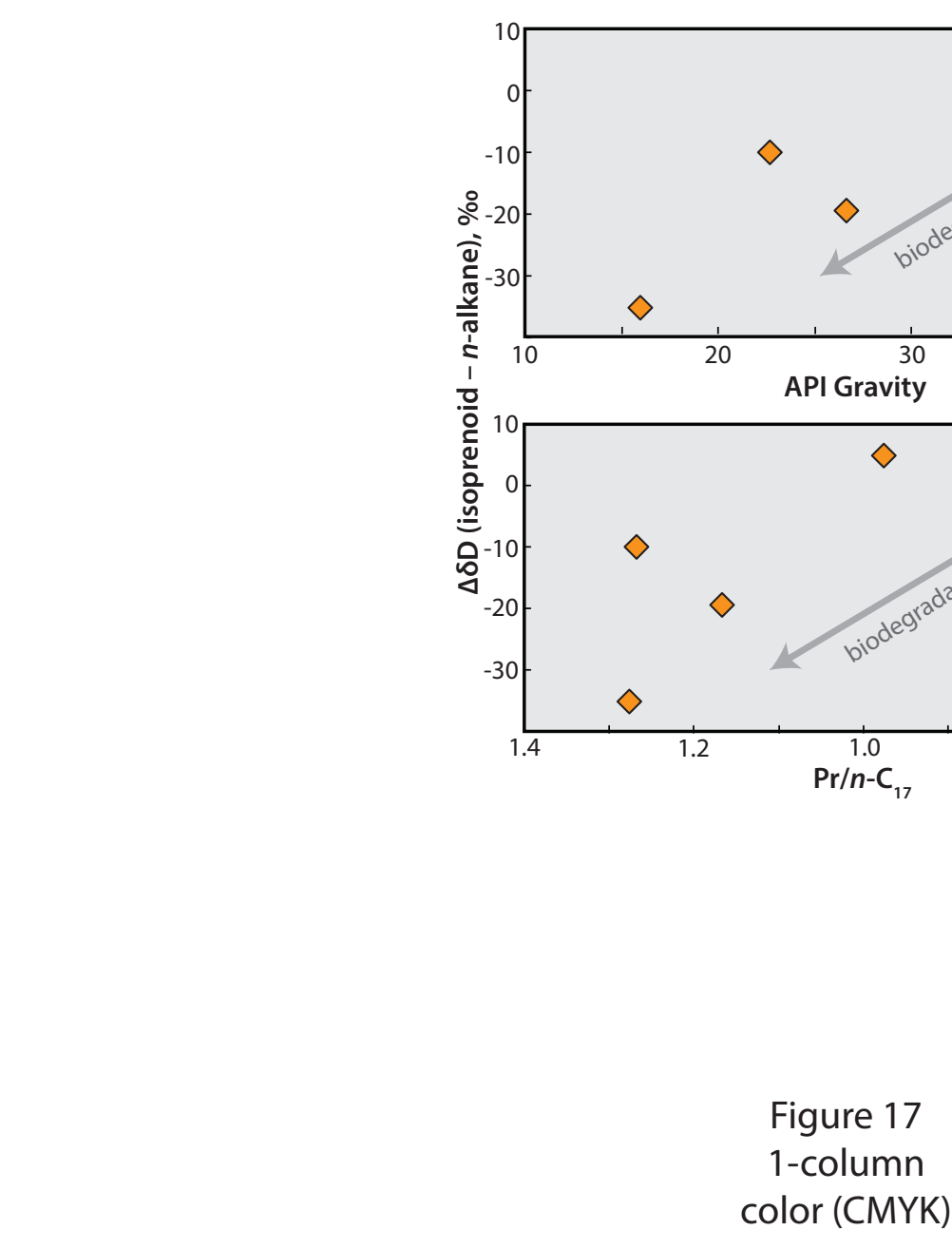

\author{
(
}

\title{
Fure 17
}

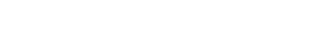

(

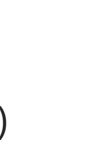

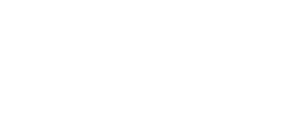

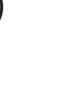

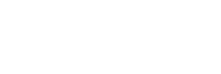




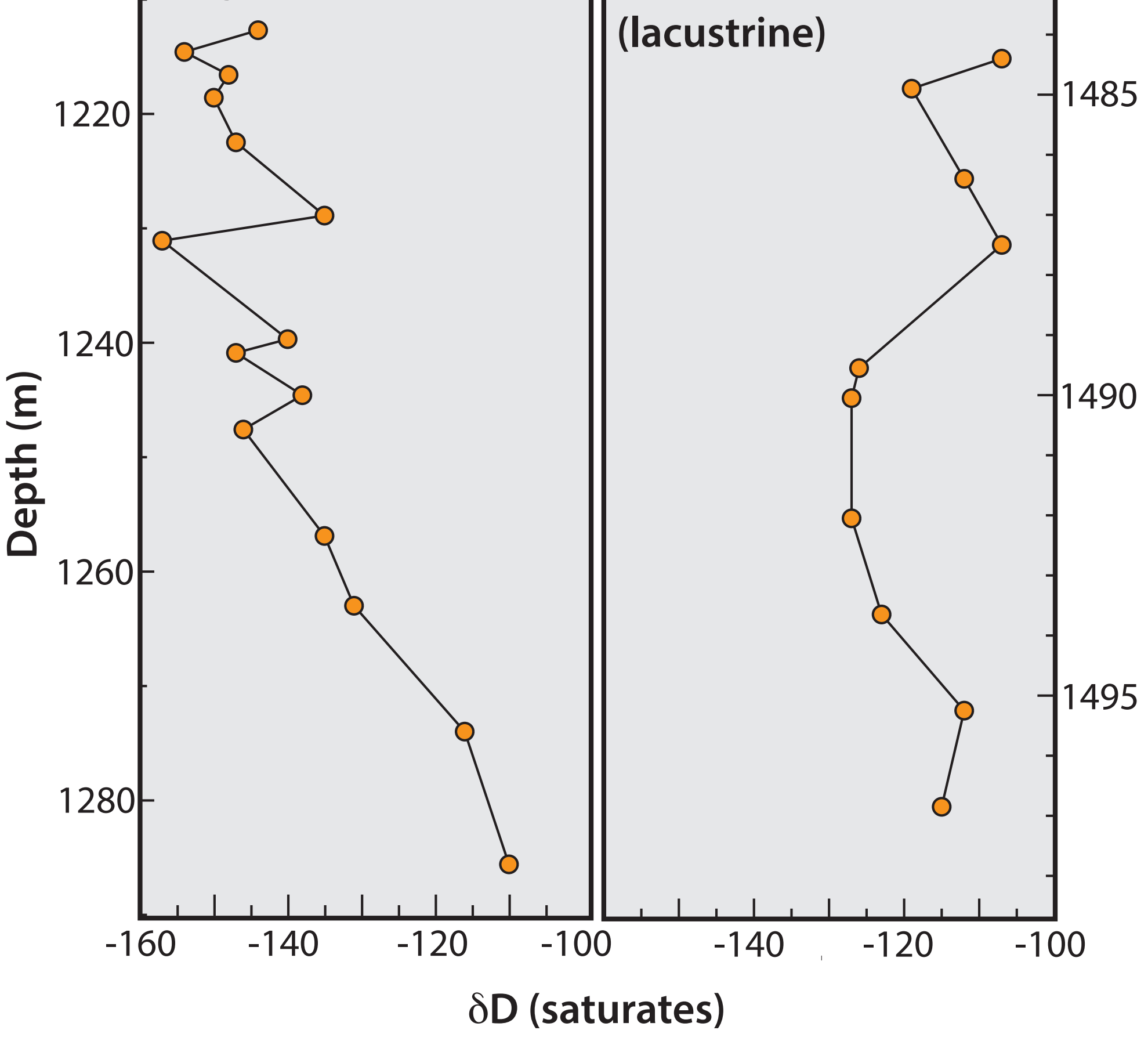

Figure 18 1-column 
U. Devonian Duvernay-derived oils in Alberta

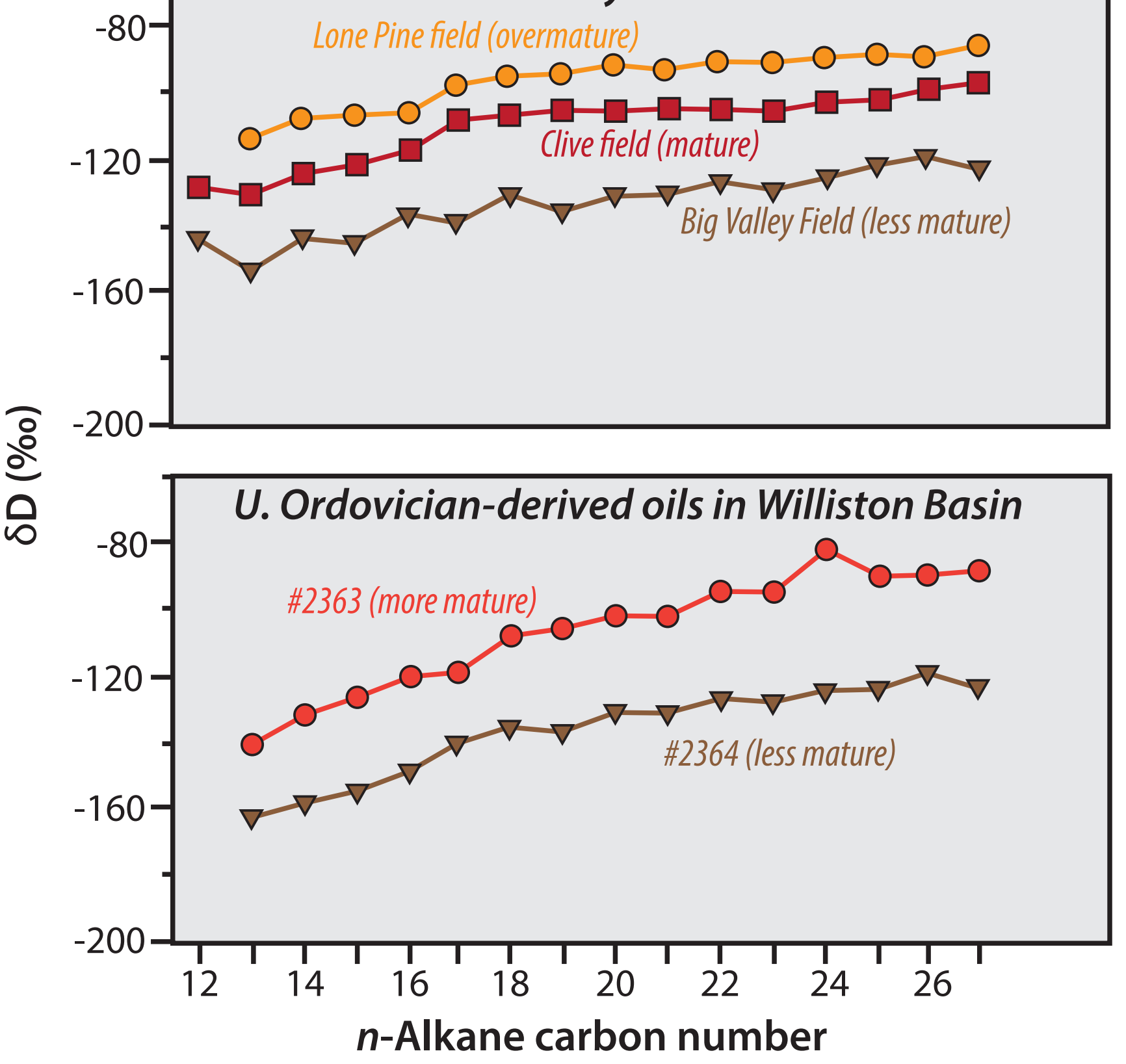

Figure 21

\section{1-column}


Figure 23

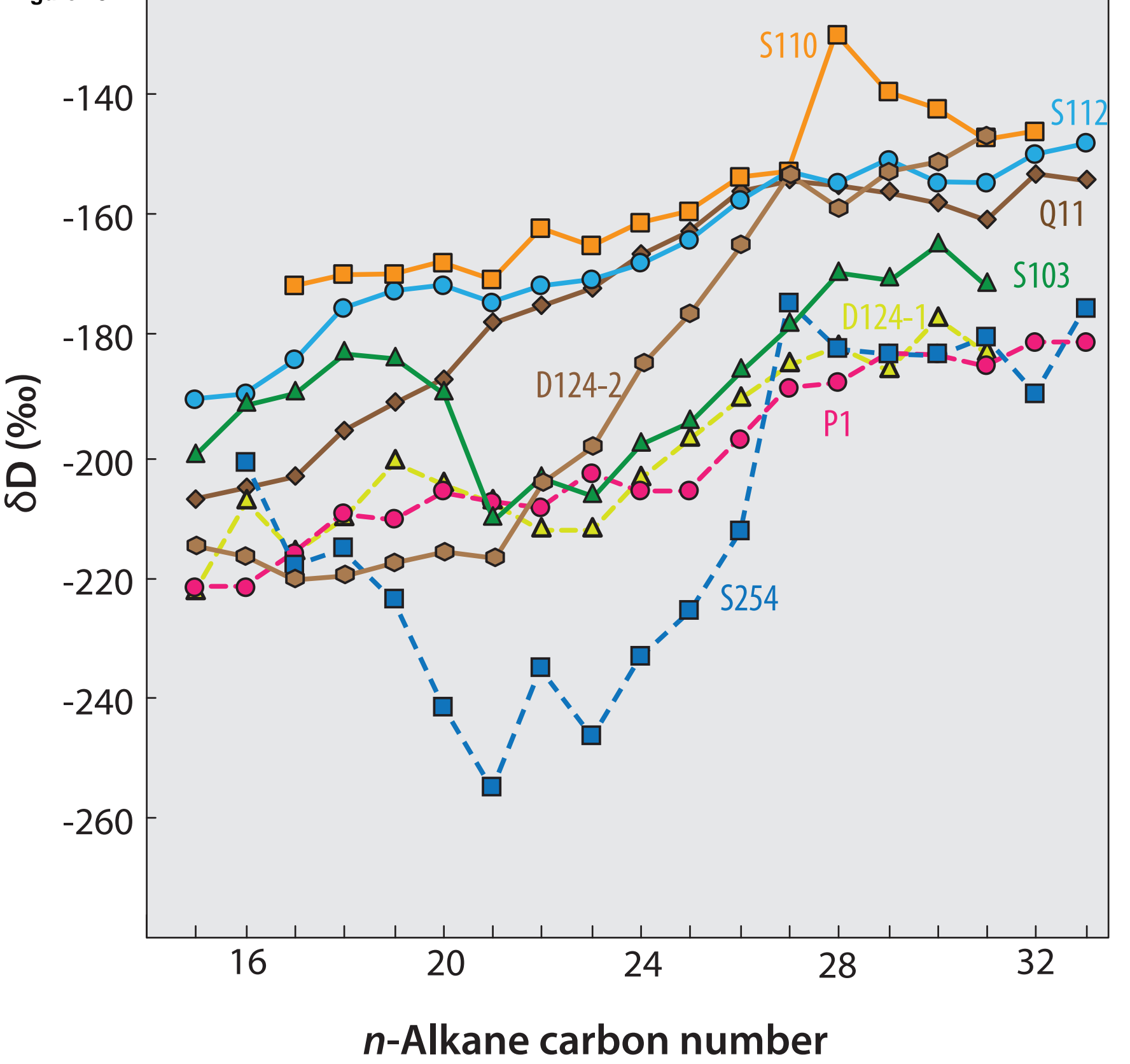

Figure 23

1-column

color (CMYK) 
Figure 24

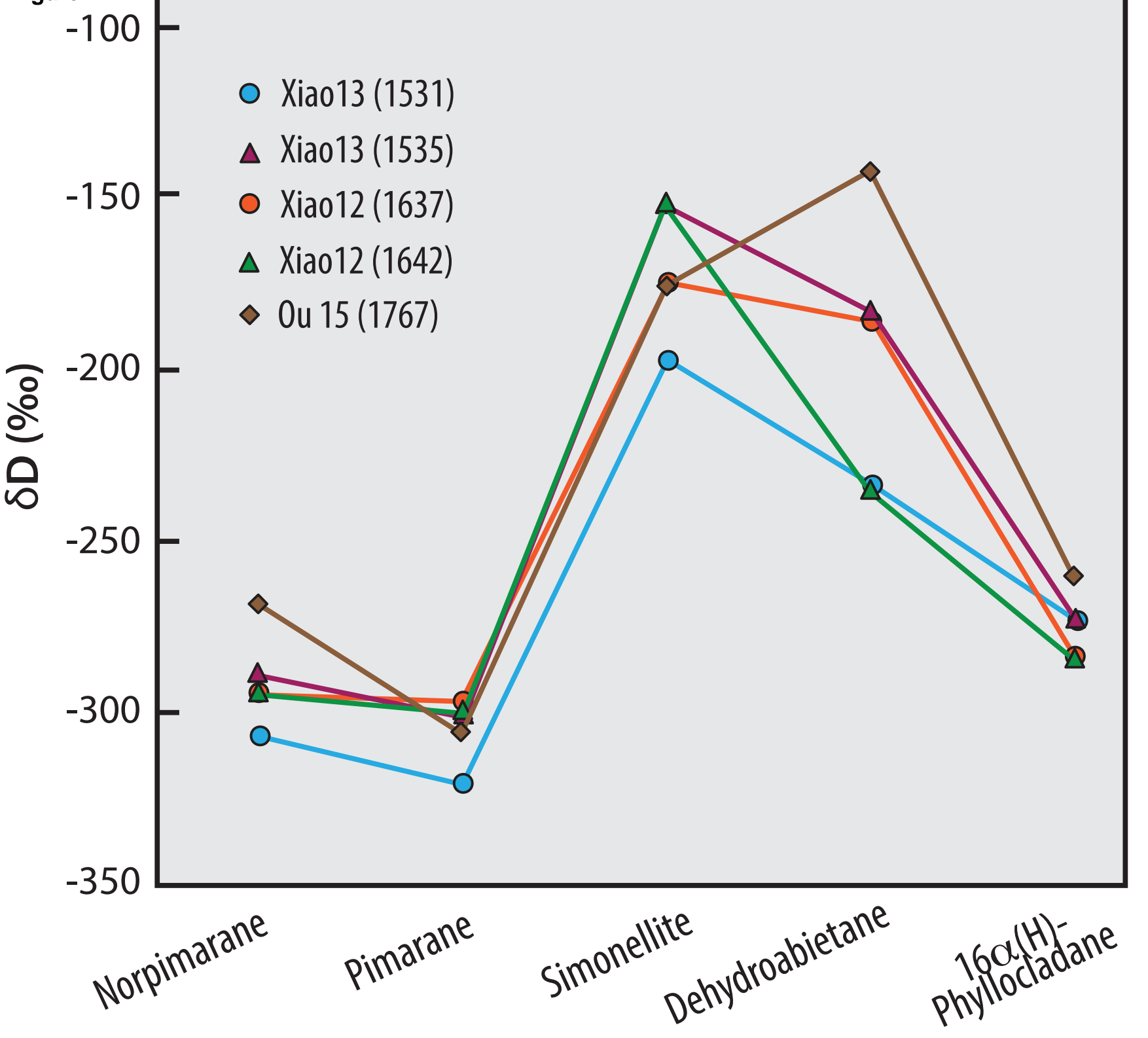

Figure 24 1-column 

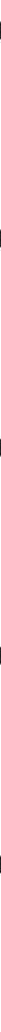

Figure 25

2-column color (CMYK) 
